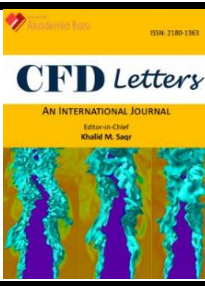

\title{
Flow Characteristics of Disk Bypass Pipeline Inspection Gauge (PIG) in Natural Gas Pipelines using Computational Fluid Dynamics
}

\author{
Md Insiat Islam Rabby ${ }^{1}$, Siti Ujila Masuri ${ }^{1,{ }^{*}}$, Ahmad Syakir Fariz Samsul Kamal ${ }^{2}$, Zulkiflle Leman ${ }^{1}$, \\ Abdul Aziz Hairuddin ${ }^{1}$, Nuraini Abdul Aziz ${ }^{1}$ \\ 1 Department of Mechanical and Manufacturing Engineering, Faculty of Engineering, Universiti Putra Malaysia, 43400 Serdang, Selangor, \\ Malaysia \\ 2 Research and Engineering Department, Eureka Efektif Sdn. Bhd., No. 32, Jalan Perindustrian Suntrack, Hub Perindustrian Suntrack, Off Jalan \\ P/1A, Seksyen 13, Bandar Baru Bangi, 43650 Bandar Baru Bangi, Selangor, Malaysia
}

ARTICLE INFO

Article history:

Received 6 January 2021

Received in revised form 7 April 2021

Accepted 9 April 2021

Available online 14 April 2021

\section{Keywords:}

Pipeline inspection gauge; Fluid velocity; differential pressure; bypass opening percentages

\section{ABSTRACT}

Disk bypass pipeline inspection gauge (PIG) is considered as an efficient device for pigging operations including cleaning, maintaining and inspecting pipelines. The PIG performance is influenced by the fluid flow characteristics as PIG moves forward due to differential pressure of fluid around the PIG. This study focuses on flow characterization of fluid around disk bypass PIG for natural gases pipelines including methane, ethane, and butane using computational fluid dynamics approach. The control volume method with steady state Turbulent $k-\epsilon$ model was applied for simulation purposes using ANSYS Fluent 19 software. Fluid velocities at different sections around PIG and differential pressure were investigated for various bypass opening percentages. The results showed that by increasing bypass opening percentages from $5 \%$ to $15 \%$, fluid velocity at bypass opening section has reduced $28.28 \%, 40.43 \%$, and $21.21 \%$ for ethane, butane, and methane, respectively, while differential pressure reduced $88 \%, 86 \%$ and $89 \%$. This indicated that $15 \%$ bypass opening percentage provided the best flow characteristics among all cases considered. At $15 \%$ bypass opening percentage, methane resulted in the lowest fluid velocity at bypass opening section and lowest differential pressure compared to others. Additionally, a correlation of differential pressure of these gases as a function of bypass opening percentage and other parameters was also developed for first time. All results are important for design selection of PIG parameters for efficient pigging operation.

\section{Introduction}

Pipeline inspection gauge (PIG) is a device used in oil and gas industries to perform pigging operations including liquid removal, cleaning debris, and inspecting pipelines [1-5]. These operations cannot be done properly if the PIG moves too quickly in addition to the risk of damaging the pipeline walls and the PIG itself [6-8]. The PIG speed is therefore considered as one of the most important concerns in pigging operations and remains a big challenge in oil and gas industries.

\footnotetext{
* Corresponding author.

E-mail address: ujila@upm.edu.my (Siti Ujila Masuri)
}

https://doi.org/10.37934/cfdl.13.4.1137 
The PIG movement is greatly influenced by the pipeline flow characteristics as the PIG propels inside the pipeline due to differential pressure developed between its tail and front [9-11]. Therefore, the flow characteristics of fluid inside the pipeline including the fluid velocity and pressure need to be determined properly in order to control the PIG speed in pigging operations $[6,12]$. Additionally, new designs of PIG have evolved from time to time in order to achieve better control of PIG speed and movement towards improving the pigging performance. Among the important developments was the introduction of a bypass hole in the PIG body through which fluid can pass $[9,13,14]$. This type of PIG, namely the bypass PIG, allows the control the PIG speed without affecting the pipeline production rate. In more recent development, a disk was introduced in front of the bypass opening section which reduces the fluid pressure at this section, and therefore controls PIG speed to be in moderate range [6].

A number of experimental and numerical studies on bypass PIG have been reported in literature with only few has considered disk bypass PIG as the latter was introduced more recently. A pigging operation has been simulated using a model that combines the equation of the PIG to the energy, momentum, and mass equations for the fluid flow [12,15-17]. Utilizing the commercial computational fluid dynamics (CFD) software, ANSYS Fluent, Singh and Henkes [18] analysed a simple bypass PIG model for both single-phase and two-phase flow.

Zhang et al., [12] carried out a numerical study on bypass PIG in the medium of water and crude oil. The study found that as the bypass hole diameter raised from 0.1 to $0.5 \mathrm{~m}$ under the specific research conditions, the PIG speed was reduced from 2.777 to $0.373 \mathrm{~m} / \mathrm{s}$ for crude oil and from 2.779 to $0.589 \mathrm{~m} / \mathrm{s}$ for water. This study concluded that the PIG speed was lowest in crude oil. Meanwhile, and Liu et al., [8], Hendrix et al., [7], Hendrix et al., [19], Hendrix et al., [20], also conducted CFD analyses on bypass PIG to predict the PIG speed. All these numerical studies considered only one type of natural gas for single-phase flow to conduct the analyses. None of the studies has considered several different gases in their analyses from which comparison of flow characteristics and PIG performance can be done.

In terms of experimental works, several studies have been performed using bypass PIG. Wang et al., [1] conducted an experimental study on bypass PIG and regular PIG for wax removal in oil flowing pipelines. Comparisons were done between the two types of PIGs and the results revealed the significantly different performances between the two PIGs. Meanwhile, Zhu et al., [14] conducted an experimental study on dynamics of rotatable bypass valve for gas pipelines to control the PIG speed. In this experiment, the relationship between differential pressure over the bypass valve, bypass valve opening, and torque can be acquired, which can provide references to PIG control algorithms.

Additionally, experiment works on bypass PIG prototype for gas pipelines has been performed by Chen et al., [10] wherein an infrared ray-based PIG velocity detection method was proposed. The results revealed that the average velocity of bypass PIG shifted linearly with the flow rate of the rear driving gas and no variation can be noticed in gas-to-PIG velocity whenever the bypass fraction was the same. With the presence of bypass fraction, the PIG speed reduced significantly and at the same time alleviated the movement fluctuation of the PIG. Moreover, Hendrix [11], Zhu et al., [21] and Chen et al., [22] also conducted experimental studies on bypass PIG to measure PIG speed and friction forces.

For studies involving disk bypass PIG, only very few were identified in the literature. Among these studies, one study was performed by Korban [23] who considered disk bypass PIG along with conventional and complex bypass PIGs for single-phase condition of gas flow by using ANSYS Fluent (version 14.5). In his study, two dimensional axisymmetric CFD model was utilized to evaluate the flow of the considered PIGs for oil and gas industry. In addition, the relationship between the governing parameters and the overall coefficient of pressure loss of the bypass PIG were evaluated 
by conducting various parametric studies. Liang [6] and Korban [23] also conducted a CFD analysis for conventional PIG, disk bypass PIG, and complex PIG for single and multiphase gas flow. Correlations of pressure loss coefficient with governing parameters were developed for these different types of PIG which showed good agreement with Idelchik and Fried's [24] correlation for a thick orifice. Hendrix [11] and Hendrix et al., [20] also studied disk bypass PIG to analyse pressure loss coefficient and friction forces for gas pipelines. According to the studies by Korban [23], Liang [6] and Azpiroz et al., [25] bypass PIG with disk provided better performance to control and reduce PIG speed compared to bypass PIG without disk. Due to the presence of the disk in front of the bypass opening section, the bypass opening area can be controlled to be smaller than the bypass entry section thereby controlling and reducing the PIG speed [6].

The review of these studies revealed that only very few studies have been done on disk bypass PIG for natural gas transporting pipelines. To the best of the authors knowledge, none of the studies has performed analyses to compare the flow characteristics of disk bypass PIG in different natural gases such as ethane, butane and methane. These natural gases are however among the common fluids transported in oil and gas industries. Therefore, it is important to investigate the flow characteristics of these gases towards improving the pigging performance using PIG. In this regard, analysis using disk bypass PIG is desired since recent studies have shown its improved performances in comparison to bypass PIG without disk. Therefore, the aim of the current study was to analyse the flow characteristics of disk bypass PIG in terms of fluid velocities and differential pressure for natural gases pipelines including methane, ethane, and butane. The velocity contours and streamline as well as pressure contour in the presence of disk bypass PIG are presented for better understanding of the flow characteristics. Additionally, a correlation of differential pressure in terms of bypass opening percentages of the PIG and other parameters for these gases was also developed for first time towards providing more valuable insights into improving pigging operations in oil and gas industries.

\section{Methodology}

Computational fluid dynamics (CFD) analysis using ANSYS Fluent 19 software was performed in this study to analyse the flow characteristics of disk bypass PIG in the considered natural gas pipelines. In this section, firstly the equations governing the motion of the flow is presented including the model for turbulent flow as well as the PIG fluid dynamics. This is followed by the description of the computational model including the boundary conditions and the parameters considered in this study.

\subsection{Governing Equations}

\subsubsection{Navier-stokes equations}

For the motion of viscous fluids, the Navier-Stokes equation is considered as governing equation which was derived from Newton's second law of motion. In this study, the fluids were considered incompressible since the pressure variation of the fluids in pipeline is small compared to the absolute pressure. The gases considered in this study were assumed to be incompressible Newtonian fluids as during flowing through the pipe the viscosities of the gases were considered constant with zero shear rate at zero shear stress. For incompressible Newtonian fluids the widely used Navier-Stokes equation is given as

$$
\rho\left(\frac{\partial \vec{u}}{\partial t}+\vec{u} \cdot \nabla \vec{u}\right)=-\nabla P+\mu \nabla^{2} \vec{u}+\vec{f}
$$


where $\rho$ is the fluid density; $\vec{u}$ is the velocity vector of three-dimensional fluids which represents the velocities in $x, y$ and $z$ direction $(u, v$ and $w) ; P$ is the fluid pressure; $\mu$ is the viscosity of the fluid and $\vec{f}$ is the body forces acting on the fluid such as gravitational force. Additionally, for the incompressible fluids the general continuity equation, which was derived from mass conservation in the system, can be presented as

$\nabla \cdot \vec{u}=0$

\subsubsection{The $k-\epsilon$ turbulence model}

The $k-\epsilon$ turbulence model is considered as the most common and applied turbulence model which has also been applied in the current study. Most of recent numerical studies that dealt with turbulent flow applied $k-\epsilon$ turbulence model including the work by Liang [6] and Talbizadeh and Keshtkar [31] for disk bypass PIG simulation [26-30]. Therefore, $k-\epsilon$ turbulence model was considered for this study also. This model consists of two equations which are turbulent kinetic energy and dissipation rate derived from the Boussinesq eddy viscosity and transport equation. The equation for Boussinesq eddy viscosity can be derived from the following equation which is related to Reynolds stress tensor as well [32].

$-\rho \overline{u_{\imath}^{\prime} u_{\jmath}^{\prime}}=\mu_{t}\left(\frac{\partial U_{i}}{\partial x_{j}}+\frac{\partial U_{j}}{\partial x_{i}}\right)-\frac{2}{3} \rho k \delta_{i j}$

where $k=\frac{1}{2} u_{i}^{\prime} u_{j}^{\prime}$ is the turbulent kinetic energy, $u^{\prime}$ is the root mean square of the fluctuating velocities, $U$ is the mean velocity, $\mu_{t}$ is the turbulent eddy viscosity, and the term $\delta_{i j}$ is the Kronecker delta. Meanwhile, the turbulent eddy viscosity is defined by the following equation

$\mu_{t}=\rho C_{\mu} \frac{k^{2}}{\epsilon}$

where $\epsilon$ is the turbulence dissipation rate and $C_{\mu}$ is a constant.

The transport equation for turbulence kinetic energy is presented in following equation [24]

$\frac{\partial}{\partial t}(\rho k)+\frac{\partial}{\partial x_{i}}\left(\rho k u_{i}\right)=\frac{\partial}{\partial x_{j}}\left[\left(\mu+\frac{\mu_{t}}{\sigma_{k}}\right) \frac{\partial k}{\partial x_{j}}\right]+G_{k}+G_{b}-\rho \epsilon-Y_{M}+S_{k}$

where $G_{k}$ is the turbulence kinetic energy production amount for the actual gradients of velocity; $G_{b}$ is the turbulence kinetic energy generation amount due to buoyancy force whereby in the current study $G_{b}=0$ since heat transfer is not taken into consideration; the fluctuating dilation is referred as $Y_{M}$ which is utilized for compressible fluid only and is ignored for incompressible fluid; $\sigma_{k}$ is the turbulent Prandtl number for $k$ while $S_{k}$ is a user-defined source term. The term $G_{k}$ can be expressed by the following equation

$G_{k}=-\rho \overline{u_{\imath}^{\prime} u_{\jmath}^{\prime}} \frac{\partial u_{j}}{\partial x_{i}}$

The transport equation for turbulence dissipation rate is given by Versteeg and Malalasekera [32]. 
$\frac{\partial}{\partial t}(\rho \epsilon)+\frac{\partial}{\partial x_{i}}\left(\rho \epsilon u_{i}\right)=\frac{\partial}{\partial x_{j}}\left[\left(\mu+\frac{\mu_{t}}{\sigma_{\epsilon}}\right) \frac{\partial \epsilon}{\partial x_{j}}\right]-\rho C_{2 \epsilon} \frac{\epsilon^{2}}{k}+C_{1 \epsilon} \frac{\epsilon}{k}\left(G_{k}+C_{3 \epsilon} G_{b}\right)+S_{\epsilon}$

where $C_{1 \epsilon}, C_{2 \epsilon}$ and $C_{3 \epsilon}$ are constants, $\sigma_{\epsilon}$ is the turbulent Prandtl number for $\epsilon$ and $S_{\epsilon}$ is a user-defined source term. For the model of realizable $k-\epsilon$, the values for these constants were taken as follows [4]:

$C_{1 \epsilon}=1.44 ; C_{2 \epsilon}=1.92 ; C_{\mu}=0.09 ; \sigma_{k}=1.0 ;$ and $\sigma_{\epsilon}=1.3$

\subsubsection{Fluid dynamics of PIG}

PIG motion in a pipeline is usually determined by force balance between the frictional force and driving pressure force $F_{P}$. By using a control volume analysis through the entire PIG, $F_{P}$ can be denoted as $F_{P}=\Delta P A$ where $\Delta P$ is the differential pressure over the PIG, i.e., between its downstream and upstream, while $A$ is the cross-sectional area of the pipe. The differential pressure $\Delta P$ is expressed as

$\Delta P=P_{u p}-P_{\text {down }}$

where $P_{u p}$ and $P_{\text {down }}$ represent the pressure at each side (upstream and downstream) of the PIG. An equation of force balance is usually applied to obtain motion of PIG with fluid flow over the pipeline which is given by Talbizadeh and Keshtkar [31].

$m \frac{d v}{d t}=\left(P_{u p}-P_{\text {down }}\right) A-m g \sin \theta-F_{c}$

where $v$ and $m$ are the velocity and mass of the PIG, respectively; $F_{c}$ is the axial contact force acting on PIG; $\theta$ is the inclination angle of PIG movement direction with respect to horizontal axis which is zero for this study; and $g$ is the gravitational acceleration.

\subsection{Computational Model and Boundary Conditions}

A two-dimensional axisymmetric pipe with disk bypass PIG was modelled in this study using ANSYS Fluent 19 software as shown in Figure 1. For simulation purpose, the model was considered as a stop condition during movement through the pipeline. The control volume method for singlephase steady state turbulent flow was employed. The flow region of fluid inside the whole pipeline was assumed turbulent and the Reynolds number was 58786 for ethane, 151958 for butane and 26569 for methane, respectively. At inlet, velocity inlet with room temperature was considered. Meanwhile, the boundary condition at outlet was set to be pressure outlet and gauge pressure was considered. In this model, the PIG was considered to be completely coupled with the pipe wall. Meanwhile, the pipe wall was considered stationary with no-slip condition. Moreover, pressure velocity coupling scheme was considered simple (steady state) solution method while spatial discretization of pressure, momentum, turbulent kinetic energy and turbulent dissipation rate were considered second order unpinned solution method under relaxation factor 0.7 for momentum, 0.8 for turbulent kinetic energy, 0.8 for turbulent dissipation rate and 1 for turbulent viscosity.

To analyse the flow characteristics of the natural gases in terms of its velocity, the fluid velocities at different positions were considered as illustrated in Figure 1, i.e., $v_{1}$ was taken as the fluid velocity at the bypass entry section, $v_{2}$ represented the fluid velocity at the horizontal bypass section, while 
$v_{3}$ indicated the fluid velocity at the bypass opening section. Meanwhile, to determine the differential pressure of the flow, pressures at two locations were considered as mentioned previously, i.e., $P_{u p}$ at the upstream and $P_{\text {down }}$ at the downstream. The parameters shown in Figure 1 are described in the next section.

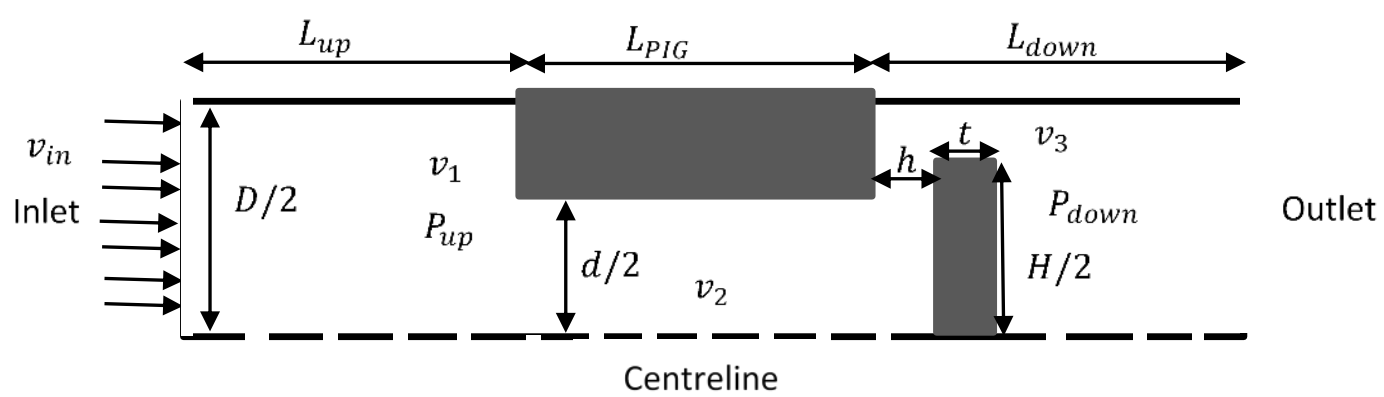

Fig. 1. Geometry of disk bypass PIG

\subsection{Parameters of PIG and Properties of Natural Gases}

The parameters of the disk bypass PIG as well as the pipe as shown in Figure 1 are provided in Table 1 while the fluid dynamics properties of the natural gases considered in this study are shown in Table 2. As seen in Figure 1, the disk bypass PIG has a disk with diameter of $H$ in front of the bypass section that makes the fluid opening area smaller than the entry and bypass section of the PIG. The distance between the disk and main body of the bypass PIG is referred to as the bypass opening section. For convenience, it is represented in terms of percentage, namely bypass opening percentages, $h$ (unit of \%). In this study, five different bypass opening percentages were considered as shown in Table 1 in order to investigate the resulting flow characteristics of the PIG.

Table 1

Parameters of pipe disk bypass PIG as shown in Figure 1

\begin{tabular}{ll}
\hline Parameters (unit) & Value \\
\hline Pipe diameter, $D(\mathrm{~mm})$ & 460 \\
Horizontal bypass PIG diameter, $d(\mathrm{~mm})$ & 195 \\
Upstream pipe length, $L_{\text {up }}(\mathrm{mm})$ & $5 D$ \\
Downstream pipe length, $L_{\text {down }}(\mathrm{mm})$ & $20 D$ \\
Horizontal bypass length, $L_{P I G}(\mathrm{~mm})$ & 610 \\
Disk diameter, $H(\mathrm{~mm})$ & 270 \\
Disk thickness, $t(\mathrm{~mm})$ & 25 \\
Bypass opening percentages, $h(\%)$ & $5,7.5,10,12.5$ and 15 \\
Inlet velocity of gases, $v_{\text {in }}(\mathrm{m} / \mathrm{s})$ & 0.94 \\
\hline
\end{tabular}

Table 2

Fluid dynamic properties of ethane, butane and methane

\begin{tabular}{llll}
\hline Property & Ethane & Butane & Methane \\
\hline Density, $\rho\left(\mathrm{kg} / \mathrm{m}^{3}\right)$ & 1.263 & 2.46 & 0.6679 \\
Viscosity, $\mu(\mathrm{kg} / \mathrm{m} . \mathrm{s})$ & $9.29 \times 10^{-6}$ & $7 \times 10^{-6}$ & $1.087 \times 10^{-5}$ \\
Reynolds number $(\mathrm{Re})$ & 58786 & 151958 & 26569 \\
\hline
\end{tabular}

\subsection{Grid Independency Test}

One of the important aspects of computational model and simulation is the grid independency test to determine the optimum number of nodes needed for the simulation. For this purpose, a 
representative case of $10 \%$ bypass opening percentage was considered and five different grid sizes as shown in Table 3 were used in this test to analyse the effect of the turbulent kinetic energy at the bypass opening section for methane. Two-dimensional structured orthogonal mesh was used in Ansys Fluent meshing tool wherein the minimum orthogonal mesh quality was 0.999512 . Since the minimum orthogonal mesh quality obtained was close to 1 , it can be concluded that the mesh quality used in this study was good. However, the results are shown in Figure 2, which demonstrates that there is no significant difference between Grid-4 and Grid-5. Therefore, for this study, Grid-4 has been used for all simulations.

\section{Table 3}

Grid number and number of nodes used as meshing for grid independency test with methane as case study

\begin{tabular}{lll}
\hline Grid no. & Number of nodes & Turbulent Kinetic Energy $(\mathrm{J} / \mathrm{kg})$ \\
\hline Grid-1 & 300206 & 0.014 \\
Grid-2 & 332066 & 0.011 \\
Grid-3 & 378096 & 0.0096 \\
Grid-4 & 404451 & 0.009 \\
Grid-5 & 414456 & 0.009 \\
\hline
\end{tabular}

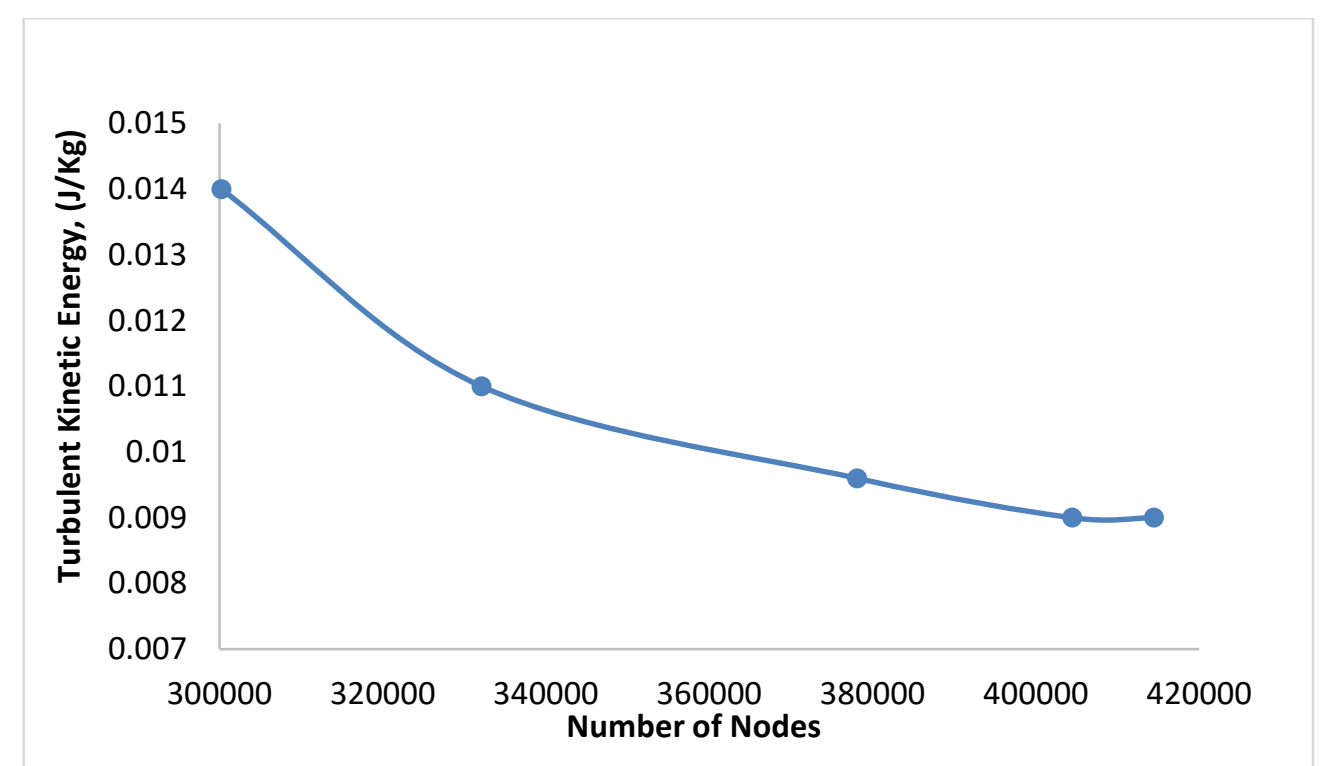

Fig. 2. Turbulent kinetic energy of disk bypass PIG with $10 \%$ bypass opening percentage as function of various grids used in grid independency test for methane as study case

\subsection{Validation}

To justify any numerical model, validation is mandatory. For this purpose, the theory of pressure loss coefficient for disk bypass PIG derived by Liang [6] was considered. The pressure loss coefficient was calculated from current CDF model and validated by using the pressure loss coefficient observed from theory. Butane with $7.5 \%, 10 \%, 12.5 \%$ and $15 \%$ bypass opening percentage was considered as representative fluid. The results are presented in Figure 3 which demonstrates that pressure loss coefficient between theory and current CFD study showed good agreement within maximum deviation below $10 \%$. The equation is given below:

$K_{d p}^{\prime}=0.5\left(1-\frac{d^{2}}{D^{2}}\right)^{3 / 4}+2 \frac{H}{d}+\frac{0.155 d^{2}}{h^{2}}-1.85$ 
where, $K_{d p}^{\prime}$ represents pressure loss coefficient for bypass PIG. Additionally, $d, D, H$ and $h$ represent diameter of bypass section, diameter of main pipe, height of disk and distance of disk from PIG body, respectively.

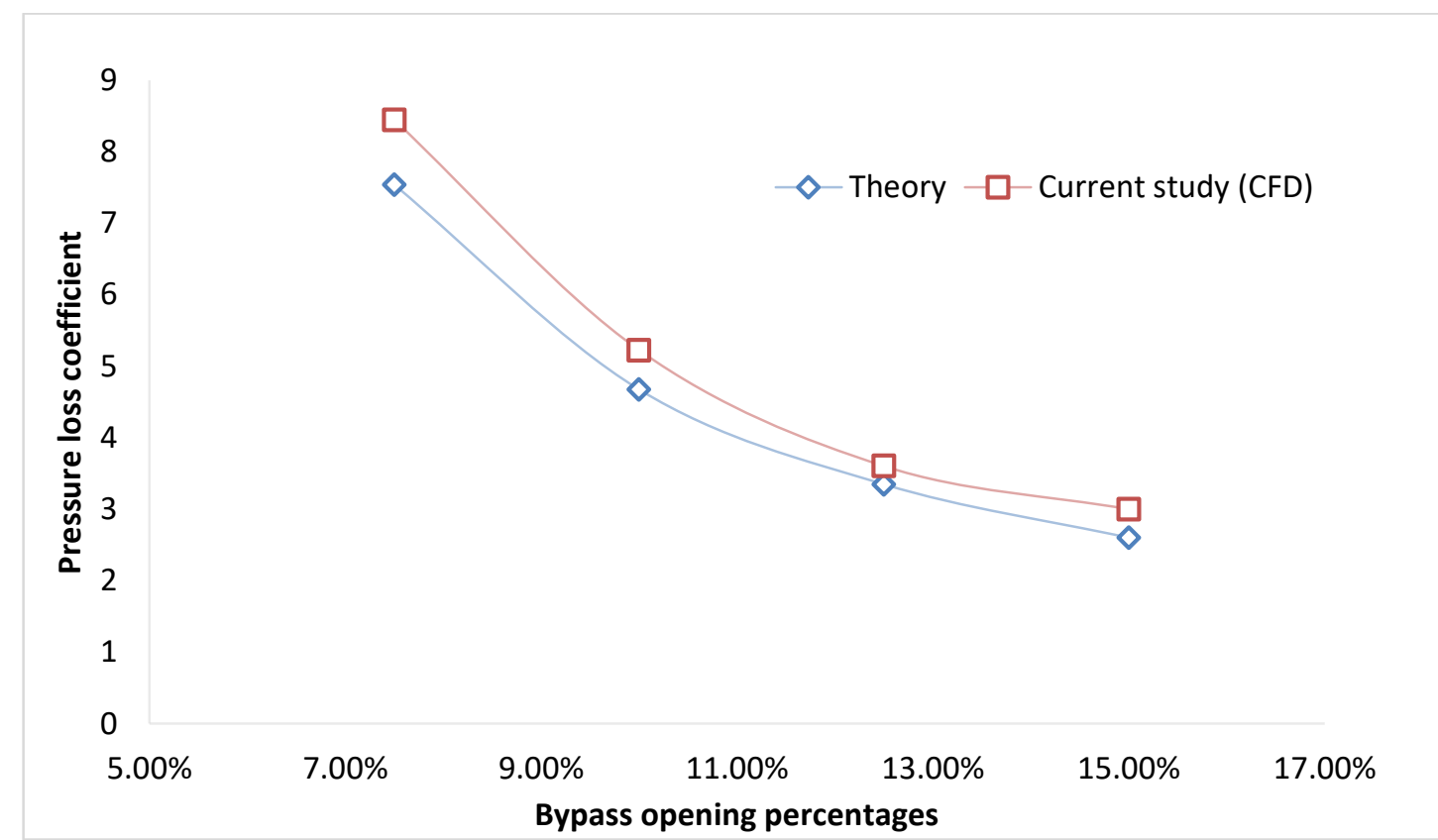

Fig. 3. Comparison of pressure loss coefficient between theory and CFD model for validation purpose

\section{Results}

In this study, simulations using the computational approach were undertaken to analyse the flow characteristics of the considered fluids around the disk bypass PIG. The results were generated and analysed in terms of the fluid velocities at different sections of the PIG, i.e., bypass entry section $\left(v_{1}\right)$, horizontal bypass section $\left(v_{2}\right)$, and bypass opening section $\left(v_{3}\right)$. These velocities are important as the PIG movement is greatly influenced by the pipeline flow characteristics $[9,11,22]$. Additionally, differential pressure was also investigated in this study since the PIG moves due to this differential pressure which is generated by the fluid around the PIG between its upstream and downstream. It is one of the key factors to predict PIG speed inside pipelines and therefore the results of differential pressure are reported in this study as part of the flow characterization of the disk bypass PIG [4].

In this study, the effects of bypass opening percentage on these velocities and differential pressure were also analysed to provide more understanding of this important feature on how it influences the flow characteristics around the PIG. Additionally, the correlation of differential pressure in terms of PIG bypass opening percentage as well as other parameters was also developed for first time to enable its prediction which is important in oil and gas pigging operations involving natural gases.

\subsection{Velocity of Different Natural Gases Around Disk Bypass PIG}

Figure 4 to Figure 6 show the fluid velocities of ethane, butane, and methane at bypass entry section $\left(v_{1}\right)$, horizontal bypass section $\left(v_{2}\right)$ and bypass opening section $\left(v_{3}\right)$ respectively, as a function of the bypass opening percentage. It can be seen from Figure 5 that for all gases $v_{1}$ did not change much as the bypass opening percentage increased. This was expected since the changes in bypass 
opening percentage did not affect the flow area at bypass entry section. Additionally, among the three gases considered in this study, methane provided the highest velocity at the bypass entry section, $v_{1}$ and the lowest velocity at the horizontal bypass section, $v_{2}$. This is due to the fluid dynamics properties of these gases. Compared to butane and ethane, methane has the lowest density and highest viscosity which make the Reynolds number of methane lowest. According to the fluid mechanics theory of Reynolds number, increase of viscosity causes reduction of fluid velocity and similarly decrease of density also causes reduction of fluid velocity.

Meanwhile, Figure 6 shows the fluid velocity at the bypass opening section, $v_{3}$. It can be observed from this figure that $v_{3}$ reduced as the bypass opening percentage increased for all the gases considered in this study. This is expected due to the presence of disk at the bypass opening section which affects the flow area in that section. As a result, $v_{3}$ was lowest at the highest bypass opening percentage which was $15 \%$ as seen in Figure 6 . The bypass opening percentage which indicates the distance between the disk and the PIG main body causes reduction of fluid velocity at this section. By increasing the bypass opening percentages from $5 \%$ to $15 \%$, fluid velocity at $v_{3}$ has reduced $28.28 \%, 40.43 \%$, and $21.21 \%$ for ethane, butane, and methane, respectively. These results indicated that bypass opening percentage of $15 \%$ provided the best flow characteristics in terms of velocity reduction in comparison to other percentages. This finding is important for better parameter selection of the PIG to achieve more efficient pigging performance.

Among the three gases, methane showed 5-21\% lower velocity at $v_{3}$ compared to ethane (for $h$ values from $15 \%$ reduced to $5 \%$ ) while $11-33 \%$ lower velocity at $v_{3}$ compared to butane. Methane has the lowest density and highest viscosity compared to ethane and butane which is the main reason for the lowest fluid velocity of methane at $v_{2}$ and $v_{3}$ compared to other gases.

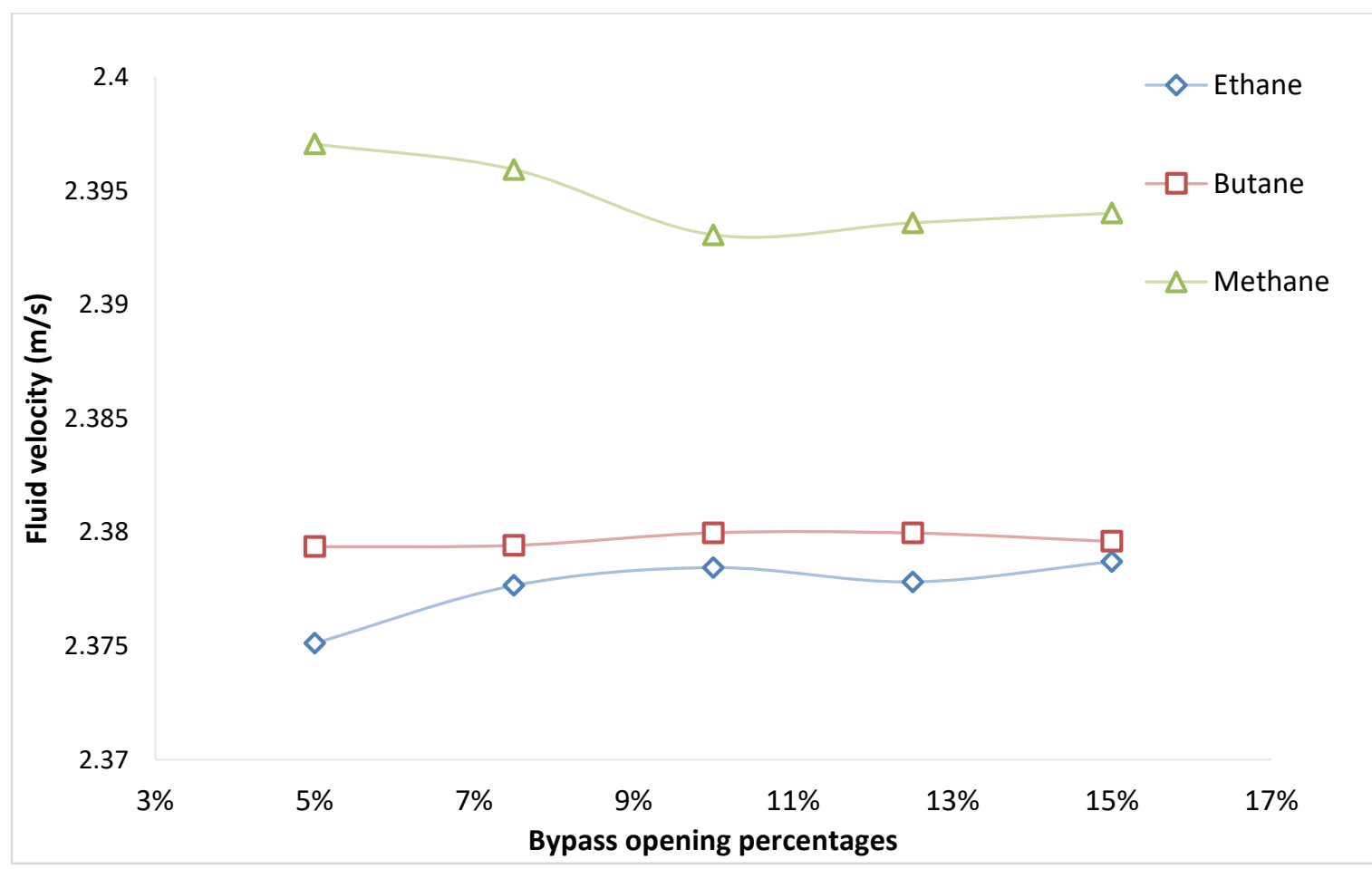

Fig. 4. Velocity at bypass entry section, $v_{1}$ as a function of bypass opening percentages for ethane, butane and methane 


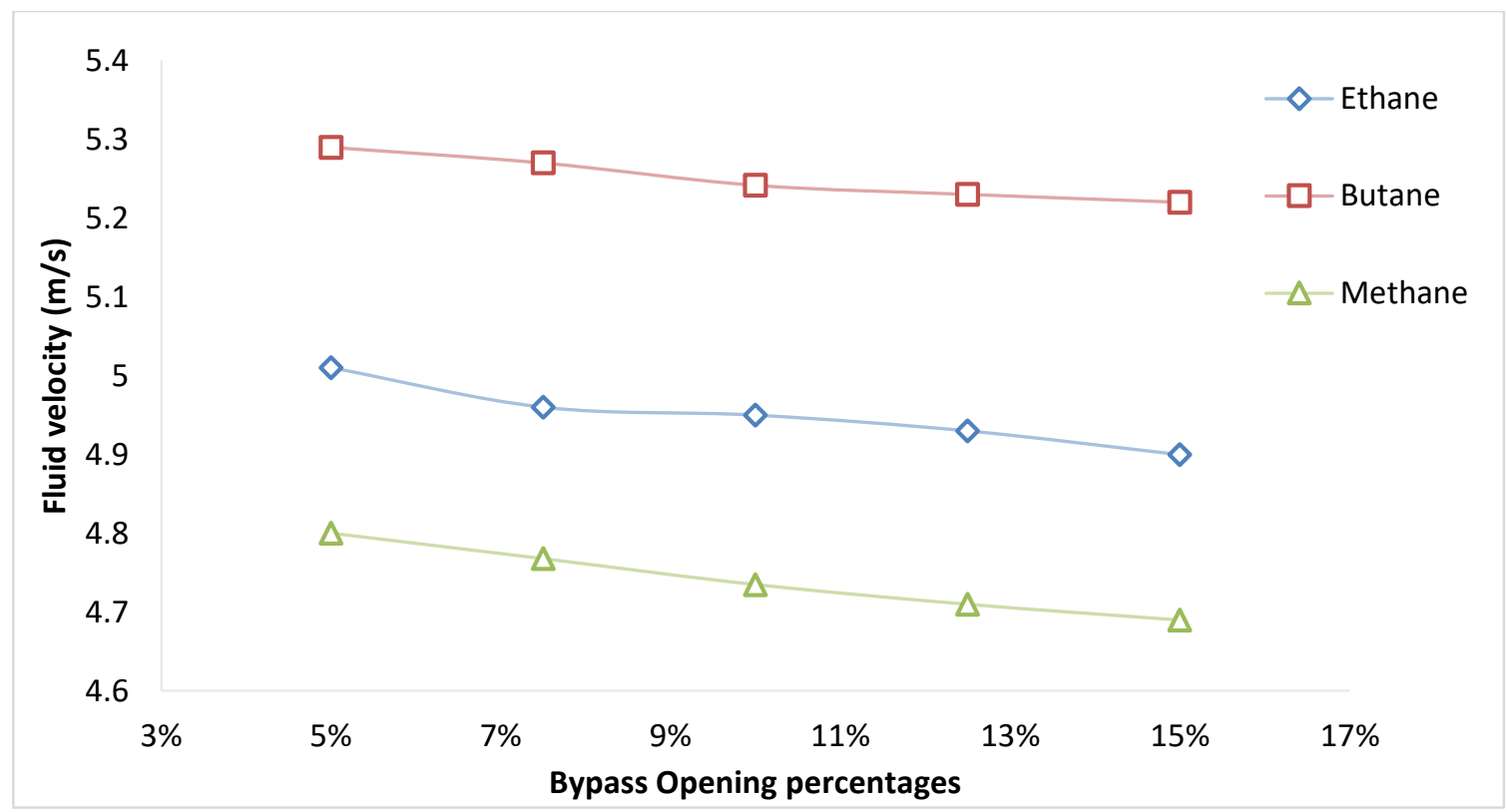

Fig. 5. Velocity at horizontal bypass section, $v_{2}$ as a function of bypass opening percentages for ethane, butane and methane

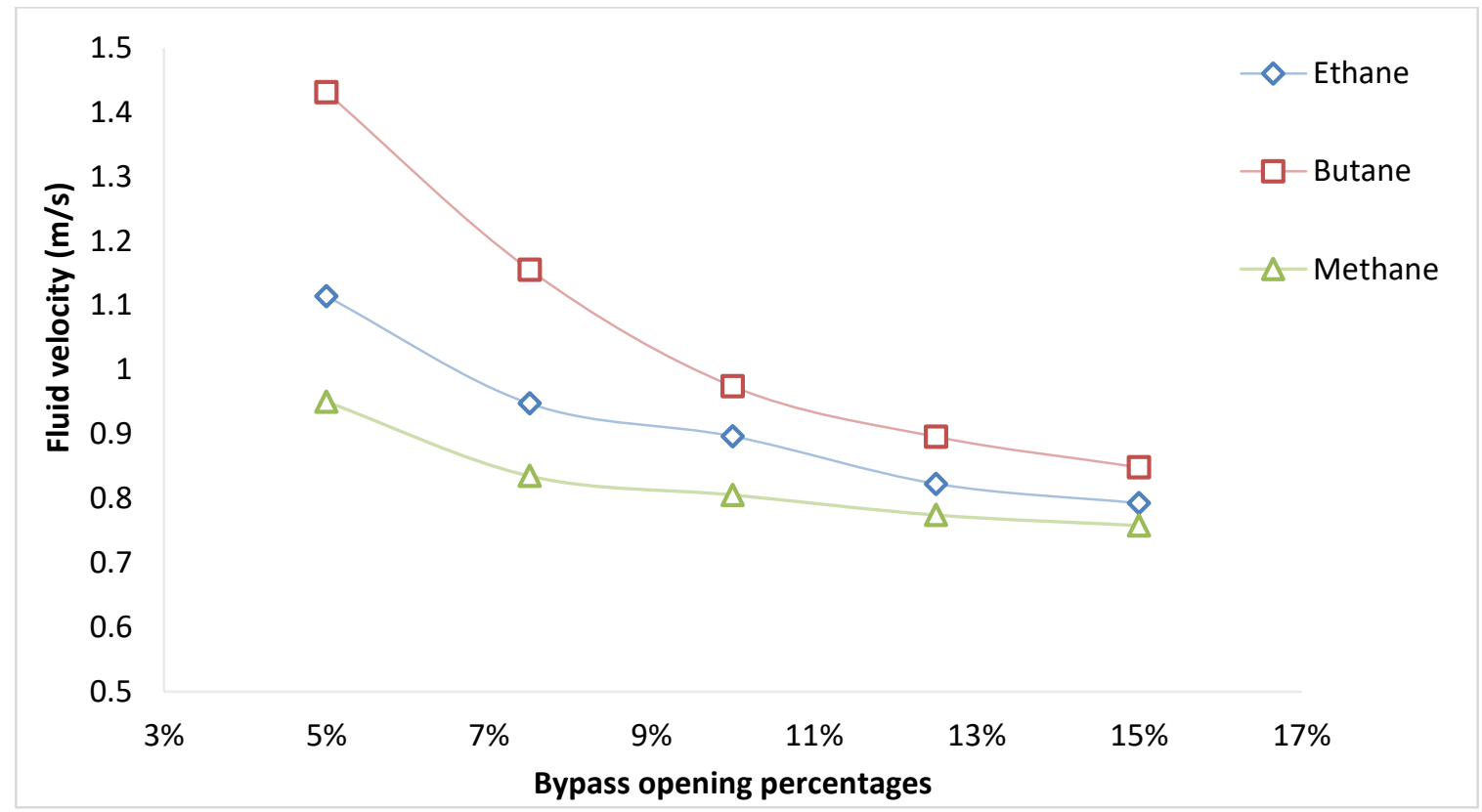

Fig. 6. Velocity at bypass opening section, $v_{3}$ as a function of bypass opening percentages for ethane, butane and methane

Table 4 and Table 5 illustrate the flow characteristics of the three natural gases around disk bypass PIG in terms of velocity contour and velocity streamline, respectively, for the five bypass opening percentages considered in this study. Observation on these figures indicated that the fluid velocity is higher at the horizontal bypass section than at the upstream and downstream section of the PIG. From Table 4, it can be seen that in horizontal bypass section fluid velocity reduced from $16.4 \mathrm{~m} / \mathrm{s}$ to $2.71 \mathrm{~m} / \mathrm{s}$ for ethane, $17.33 \mathrm{~m} / \mathrm{s}$ to $2.89 \mathrm{~m} / \mathrm{s}$ for butane and $15.62 \mathrm{~m} / \mathrm{s}$ to $2.60 \mathrm{~m} / \mathrm{s}$ for methane, respectively, at $5 \%$ bypass opening percentage. Meanwhile, at $15 \%$ bypass opening percentage the reduction in velocity was observed to be $10.16-0.63 \mathrm{~m} / \mathrm{s}, 10.91-0.68 \mathrm{~m} / \mathrm{s}$, and 9.29$0.58 \mathrm{~m} / \mathrm{s}$ for ethane, butane and methane, respectively. This shows the influence of the bypass opening percentage on reducing the fluid velocity at this section of the PIG by controlling the bypass 
area. Additionally, these results show that among the three natural gases considered in this study, methane provided lowest ranges for velocity at horizontal bypass section compared to other natural gases.

\section{Table 4}

Velocity contour of ethane, butane and methane for the five different bypass opening percentages

Bypass Gas Velocity contour

opening

\section{percentages}

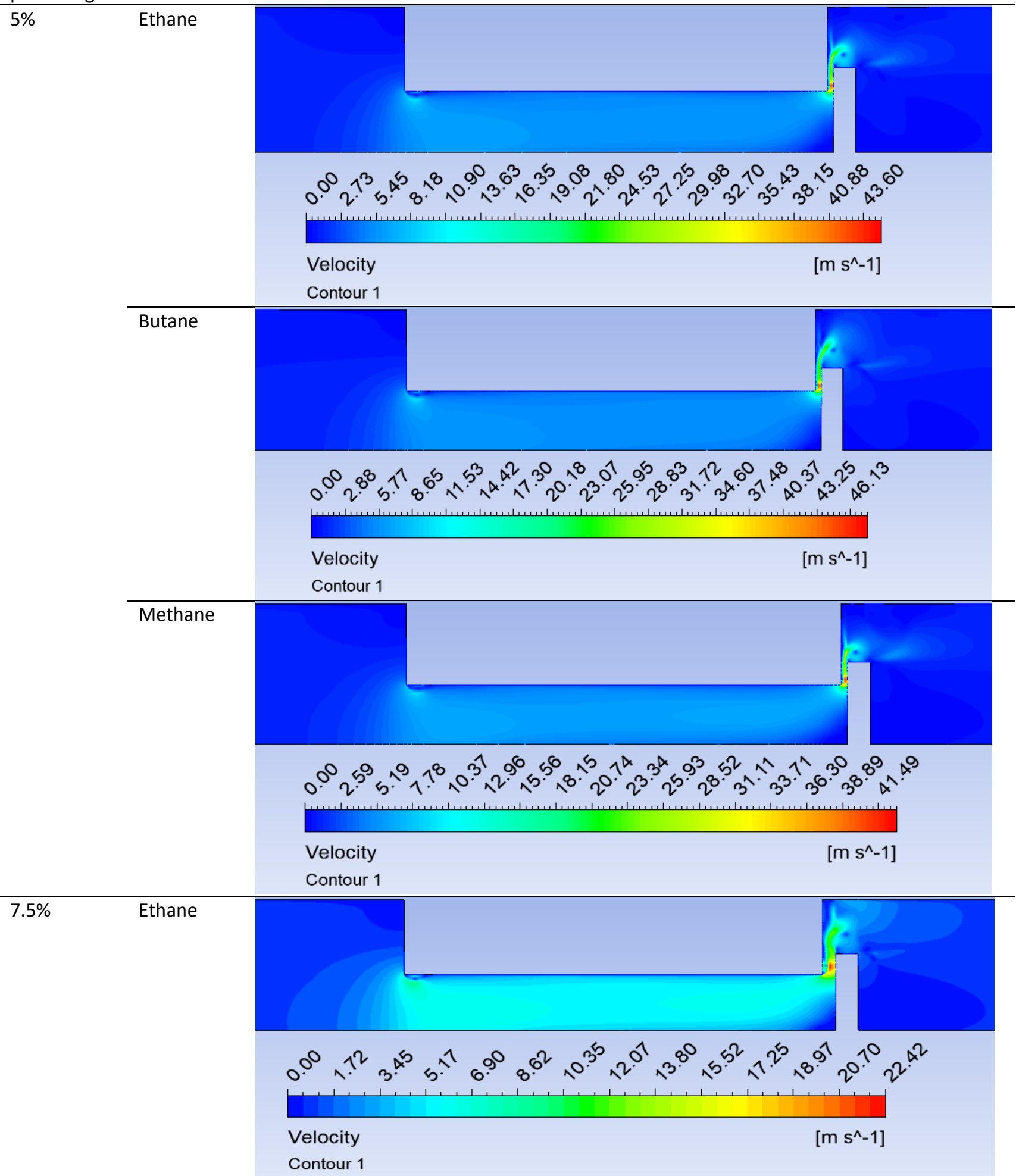




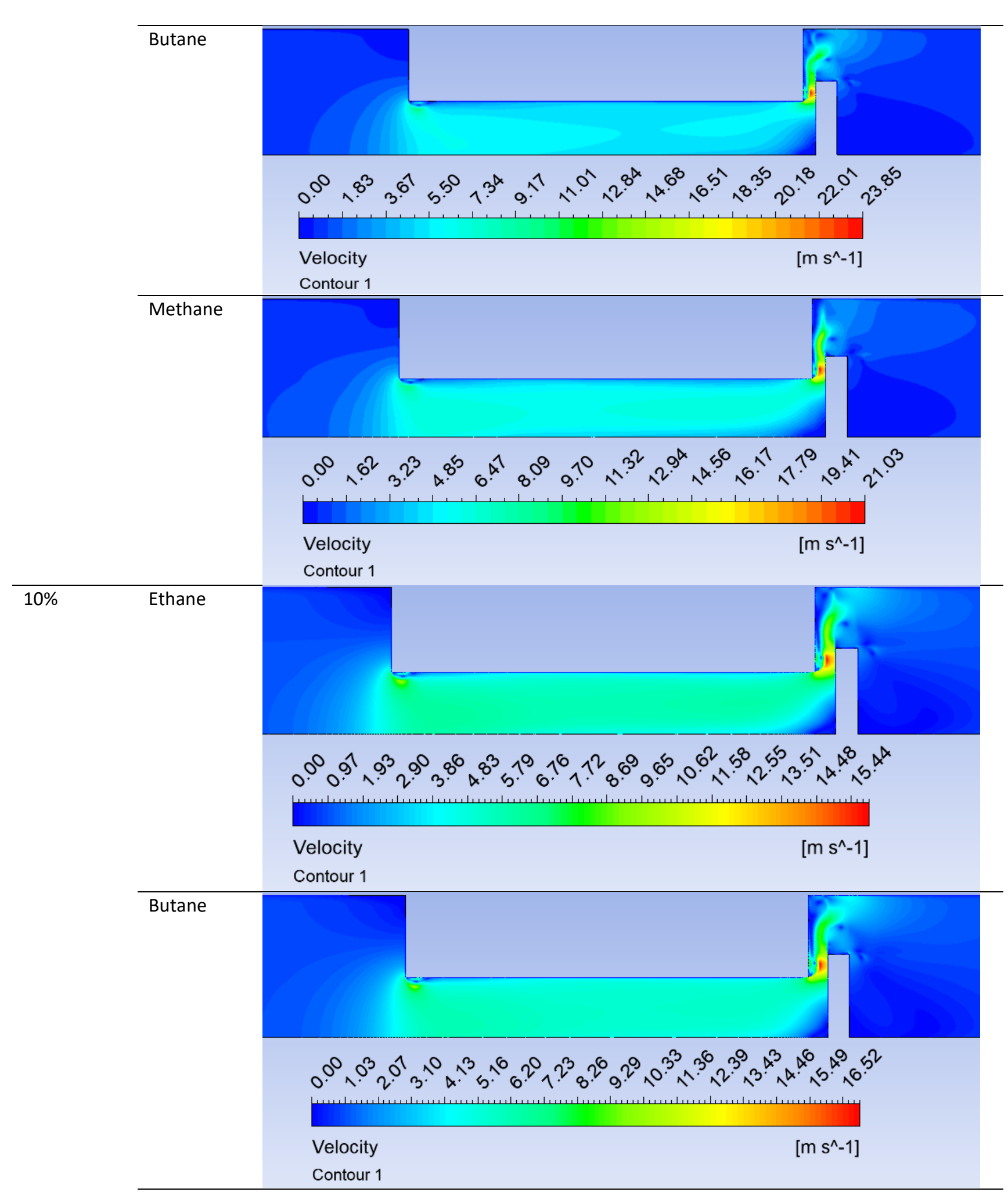




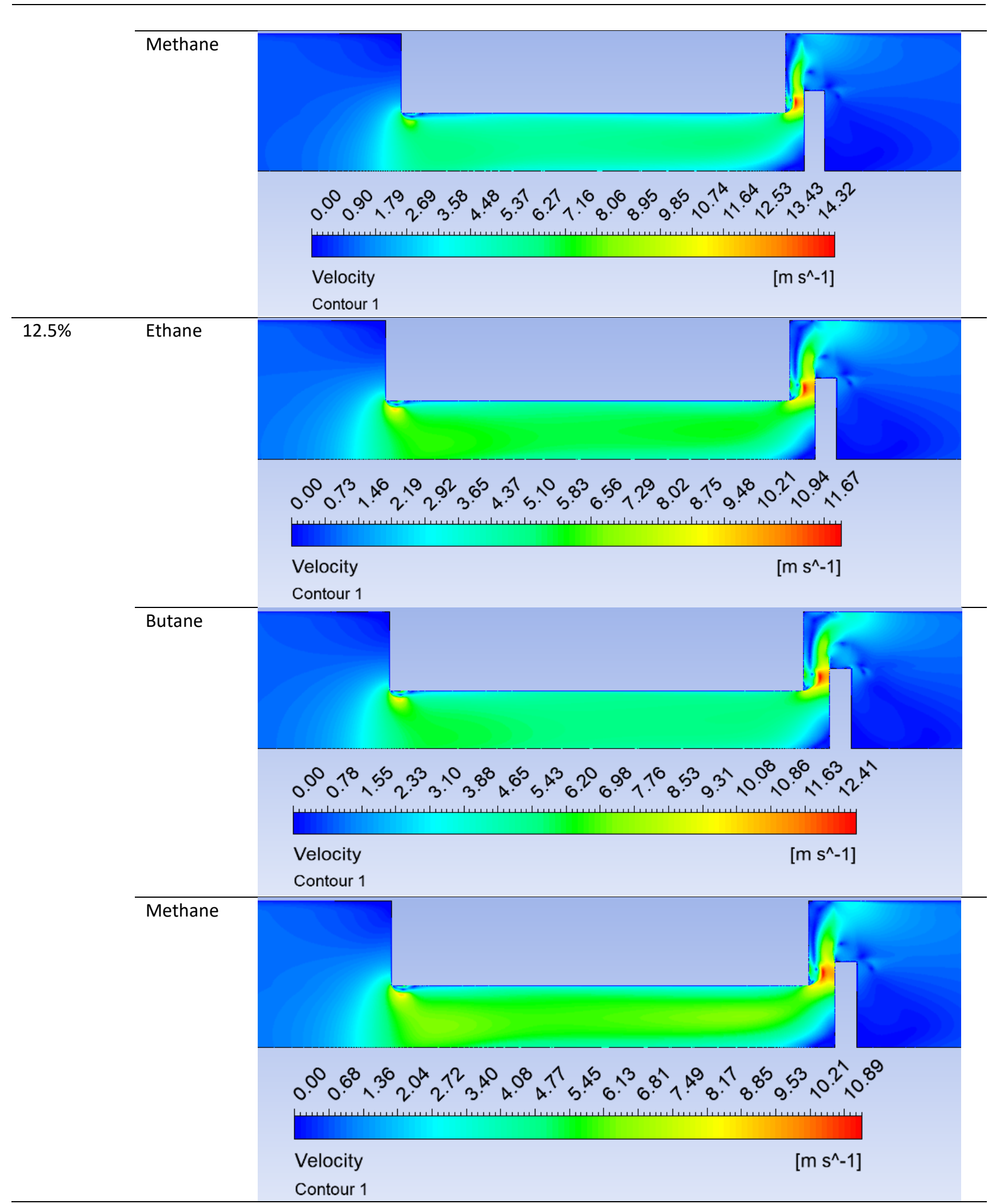




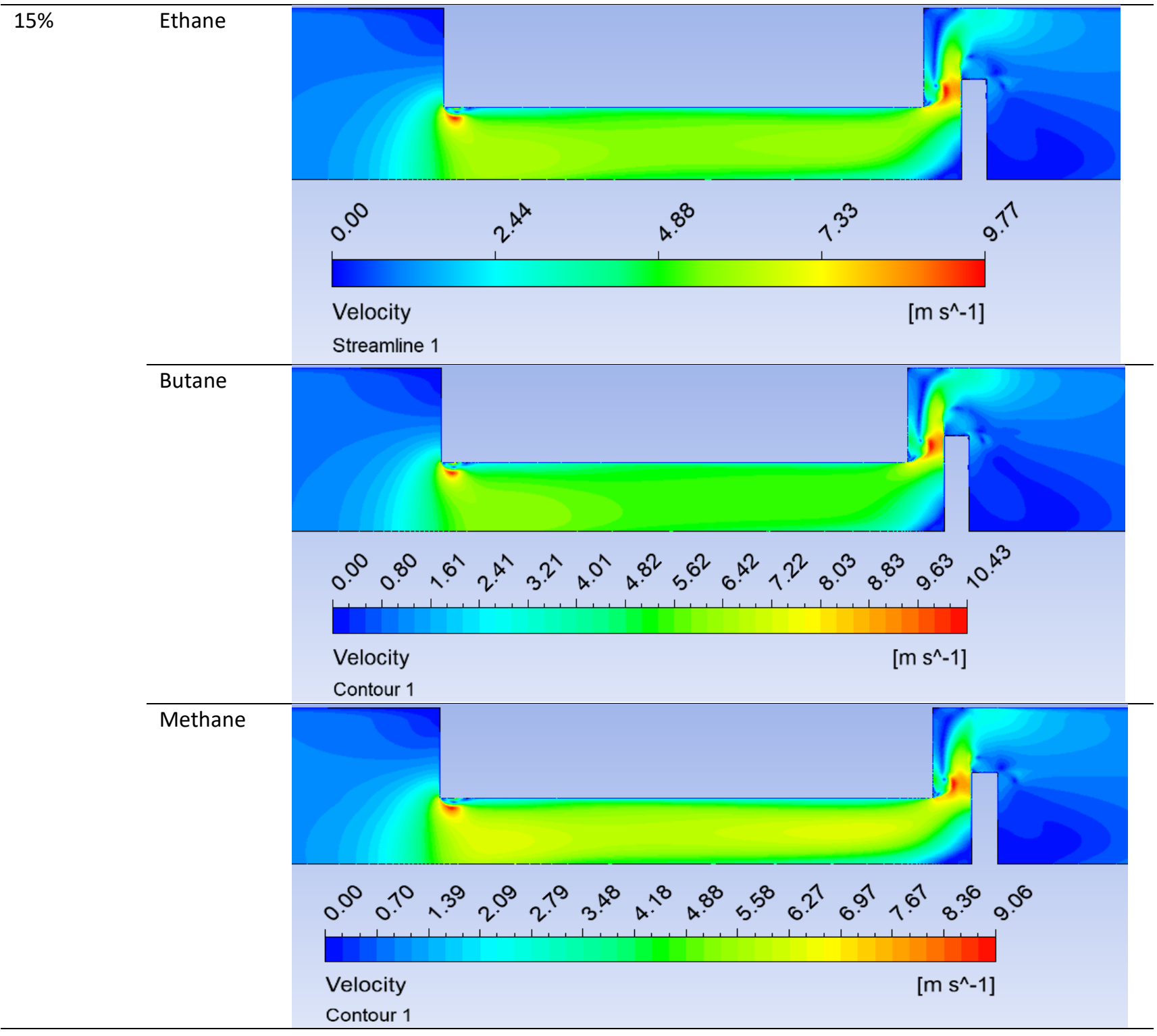

From Table 5 , it was observed that at $5 \%$ bypass opening percentage, maximum fluid velocities were $44.96 \mathrm{~m} / \mathrm{s}, 47.58 \mathrm{~m} / \mathrm{s}$ and $42.78 \mathrm{~m} / \mathrm{s}$ for ethane, butane and methane respectively. Meanwhile, at $15 \%$ bypass opening percentage, maximum fluid velocities were $9.97 \mathrm{~m} / \mathrm{s}, 10.43 \mathrm{~m} / \mathrm{s}$ and $9.06 \mathrm{~m} / \mathrm{s}$ for these fluids, respectively. Therefore, from these results it was demonstrated that by increasing the bypass opening percentages from $5 \%$ to $15 \%$, maximum fluid velocities reduced almost $76.6 \%$, $76.4 \%$, and $77.6 \%$ for these gases, respectively. Additionally, among these gases, methane provided the lowest value for maximum velocity while butane shows the highest compared to others. Table 5 also shows formation of vortices at bypass opening section. Presence of disk at bypass opening section and sudden expansion of fluid flow area created recirculation zone around disk which mainly formed vortices. Meanwhile, shear resulting from the no slip condition over boundary layers of disk, PIG and downstream wall was another key reason for the formation of these vortices. According to continuum mechanics theory, vortices have significant impact on fluid flow over a body. The streamlines in Table 5 illustrate that formation of these vorticities at the bypass opening section reduced the velocity of fluid at this section compared to bypass entry section and horizontal bypass section of the PIG. 


\section{Table 5}

Velocity streamline of ethane, butane and methane for the five different bypass opening percentages Bypass Gas Velocity streamline opening

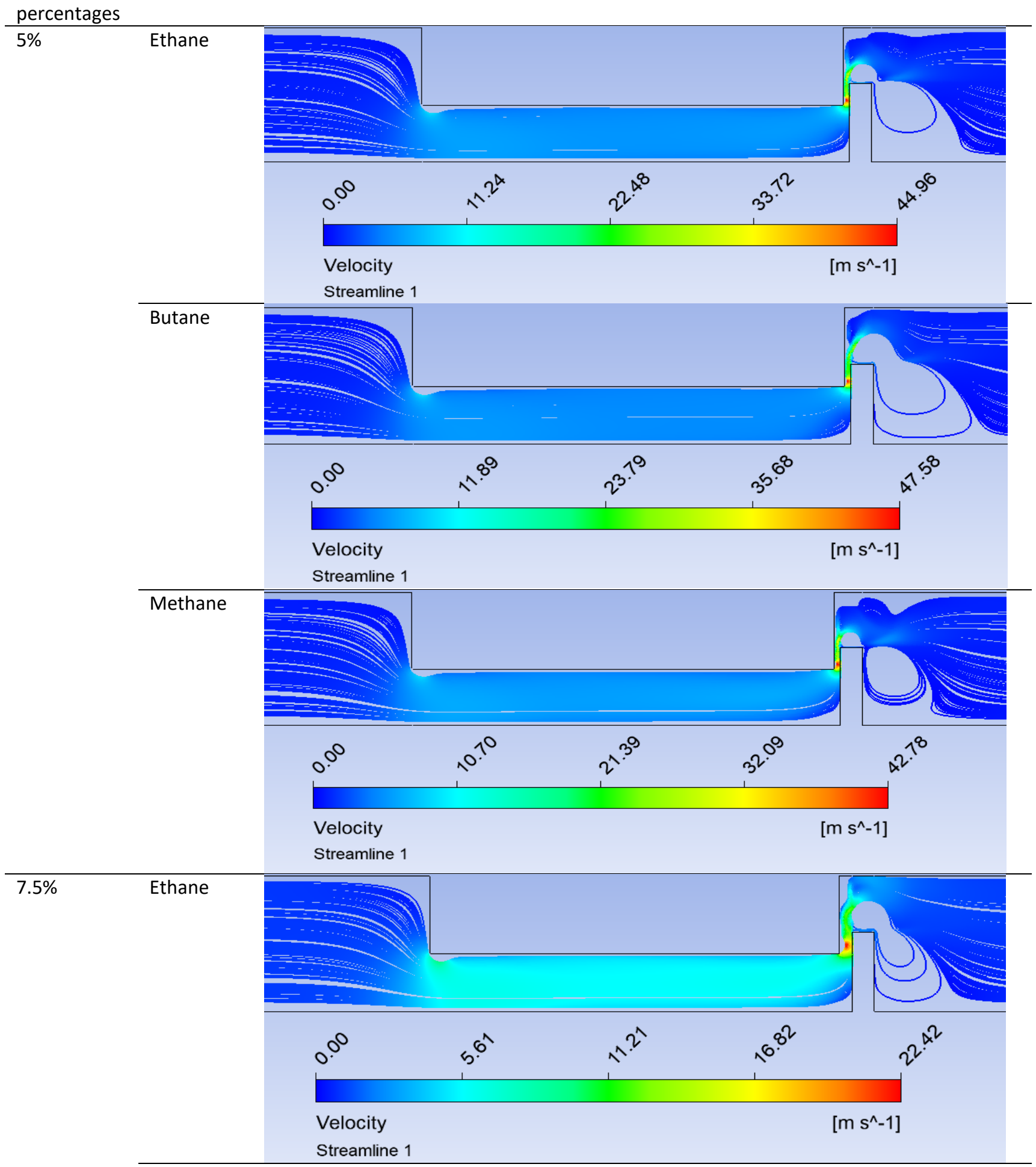




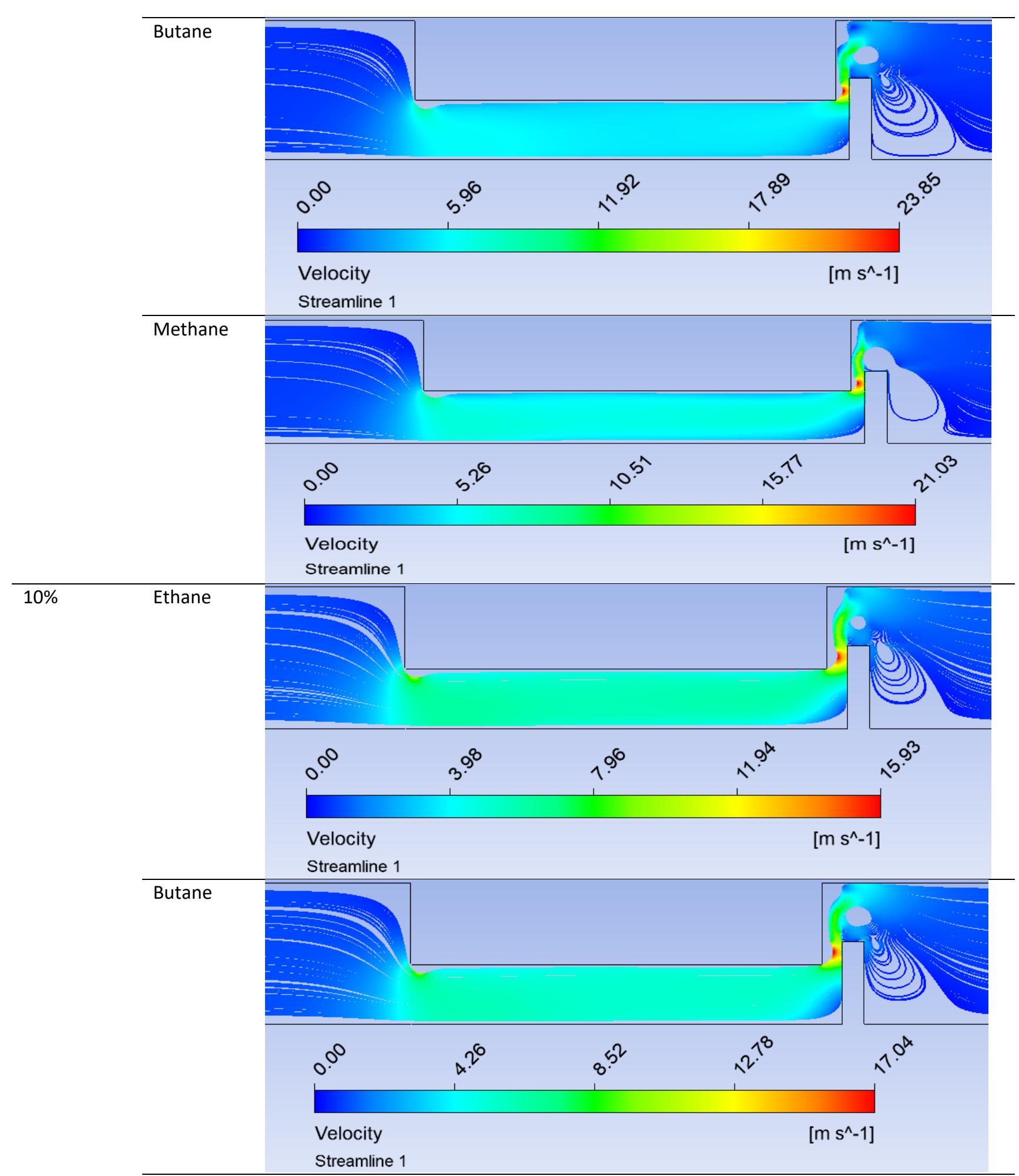




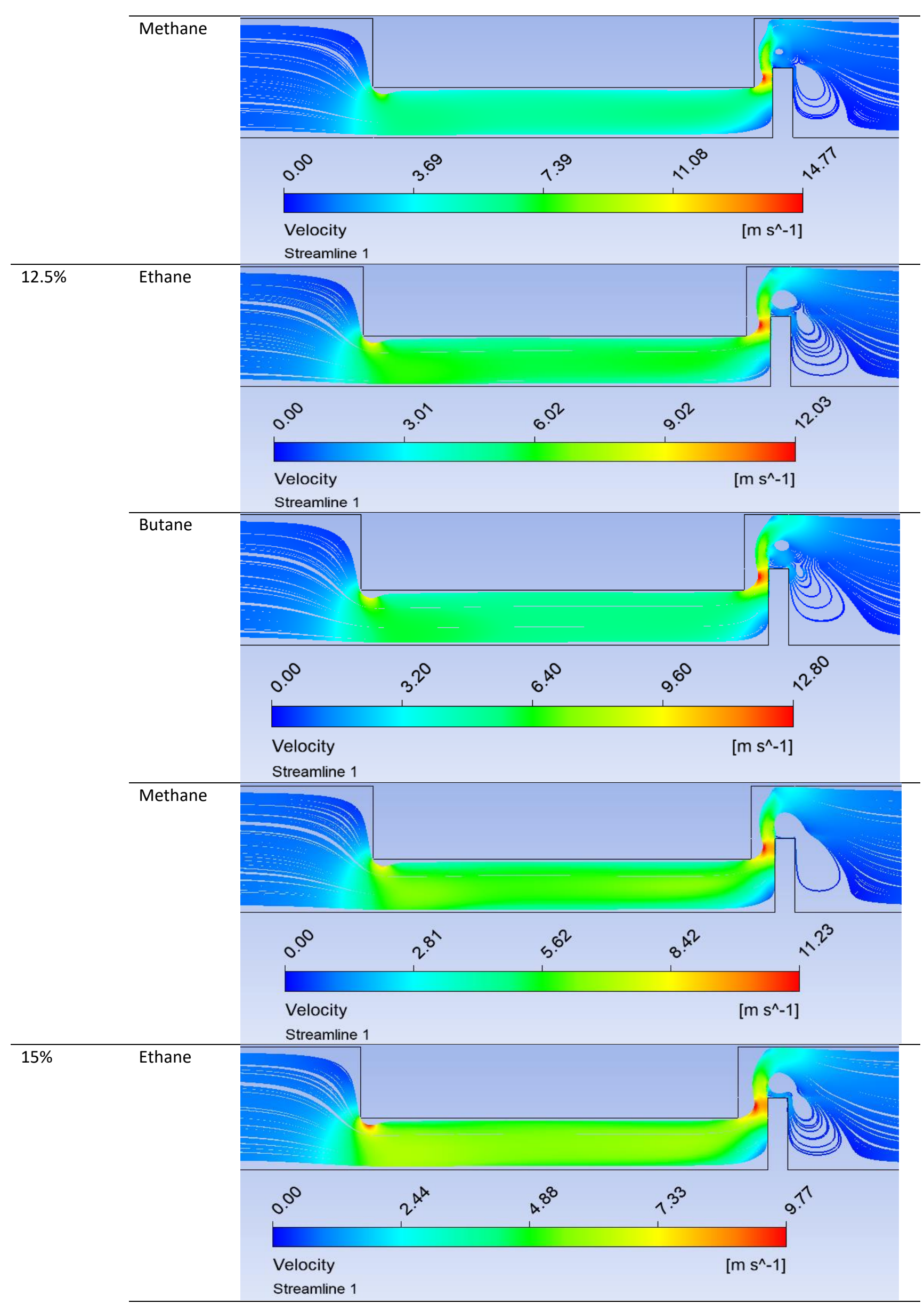




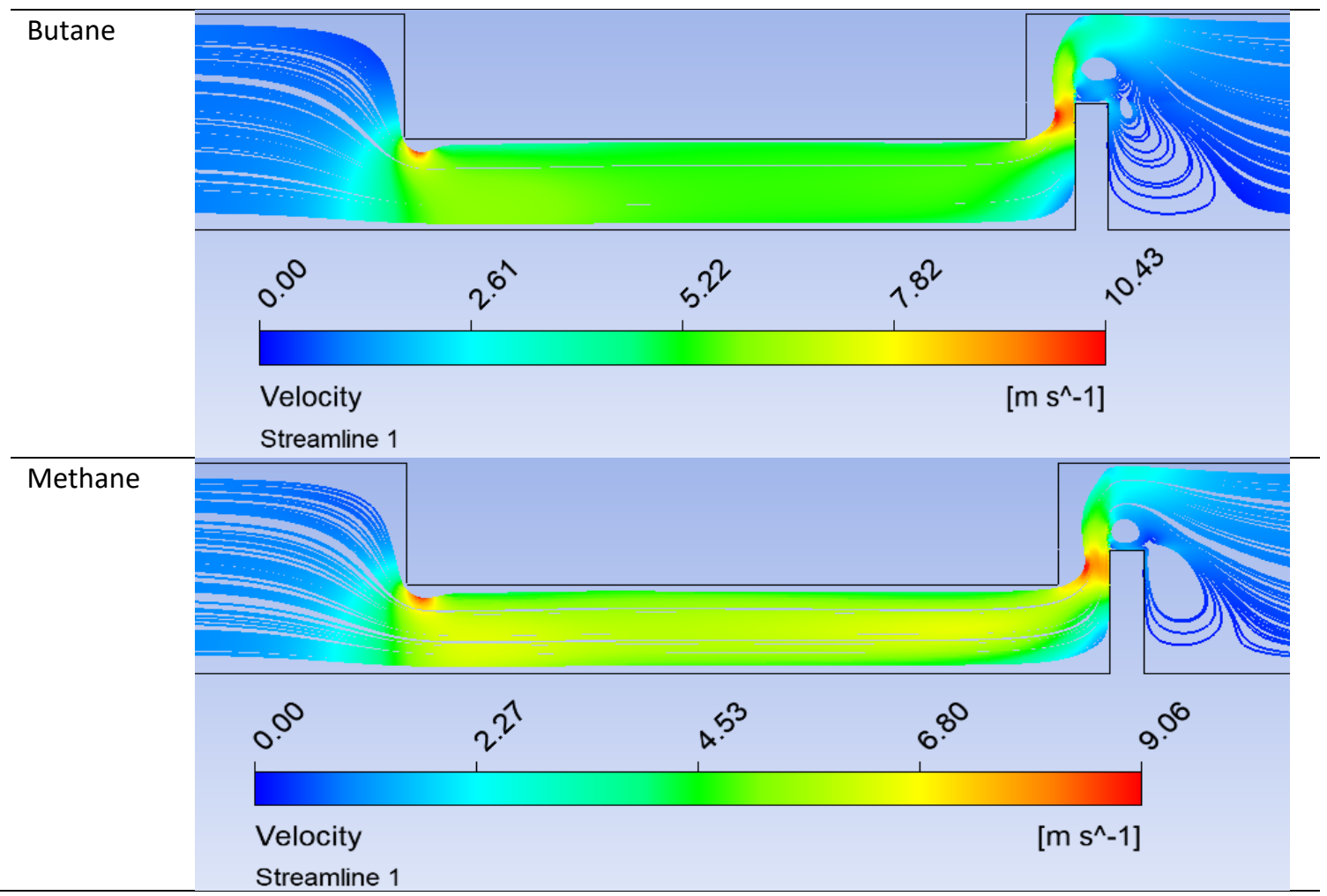

\subsection{Differential Pressure of Different Natural Gases Around Disk Bypass PIG}

Figure 7 shows the differential pressure of the considered natural gases between the upstream and downstream of the PIG section as a function of the bypass opening percentage. Results demonstrated that by increasing the bypass opening percentages, differential pressure decreased for all gases. With the increase of bypass opening percentage from $5 \%$ to $15 \%$ the differential pressure has reduced $86 \%, 84 \%$, and $88 \%$ for ethane, butane, and methane, respectively. At constant rate of fluid flow, smaller flow passing area results in higher fluid velocity at the inlet and outlet of the valve. This causes the fluid to generate more energy loss as it passes through the bypass valve, which in turn produces a larger pressure drop. This result is important as it indicated that the $15 \%$ bypass opening percentage performed better in terms of minimizing the differential pressure between upstream and downstream of the PIG section which is desirable for more efficient pigging operation. This finding was noted to be consistent with that for velocity reduction as discussed above. Therefore, it can be concluded that bypass opening percentage of $15 \%$ provided the best flow characteristics of the natural gases considered in this study. Additionally, methane showed a maximum $51 \%$ reduction of differential pressure compared to ethane and a $77 \%$ reduction of differential pressure compared to butane due to fluid dynamics properties of methane compared to the other gases. As seen in Table 2, methane has the lowest density and highest viscosity compared to butane and ethane, combination of which make the Reynolds number of methane being the lowest. According to fluid mechanics theory, the lower the density of the fluid, the smaller the energy loss and pressure drop. Similarly, lower Reynolds number which is a ratio of density and viscosity will also reduce the fluid velocity which causes lower energy and pressure loss in bypass opening section. 


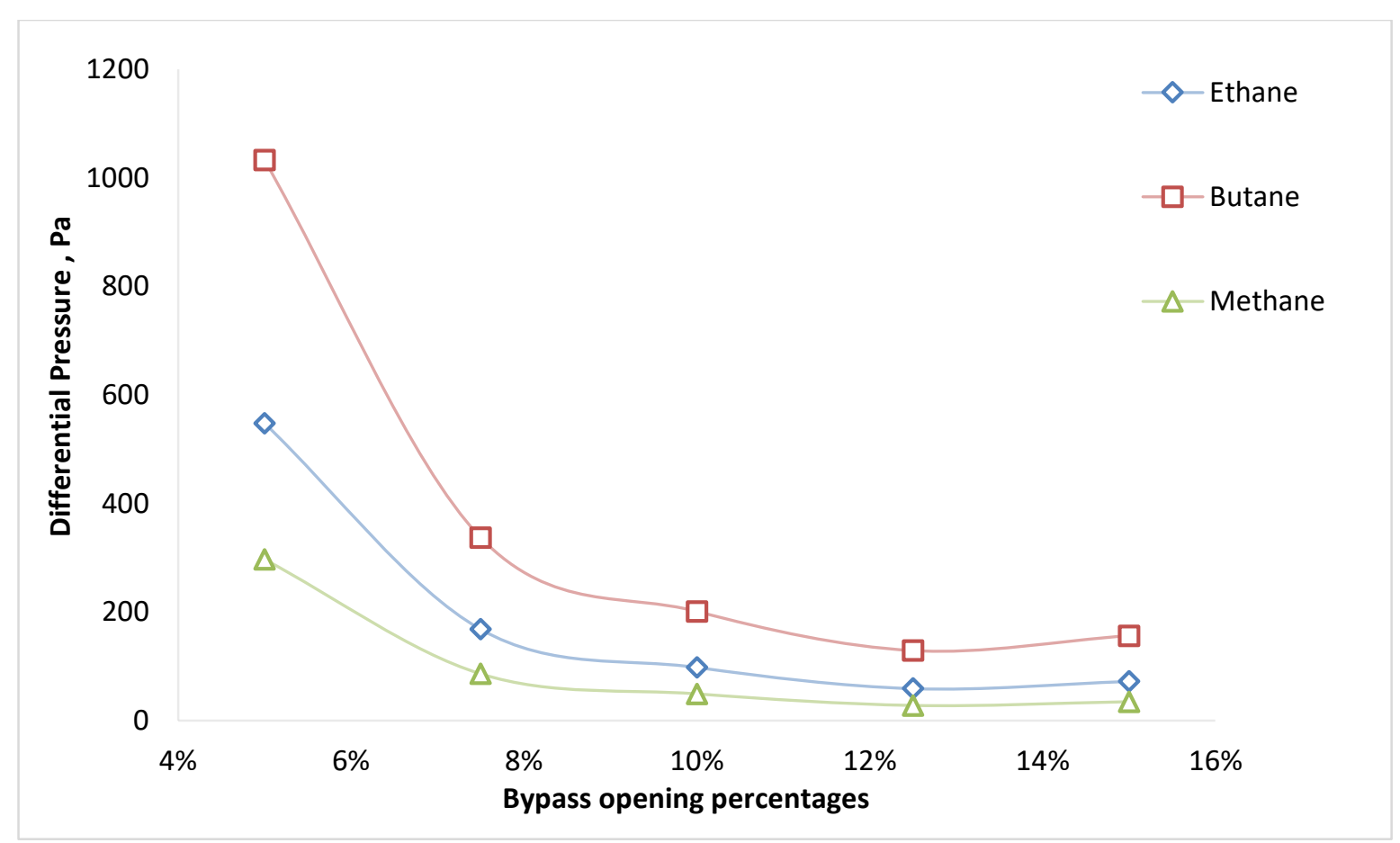

Fig. 7. Differential pressure between upstream and downstream of disk bypass PIG section as a function of bypass opening percentages for ethane, butane and methane

Table 6 shows the pressure contour between upstream and downstream of PIG section for the different gases at the five bypass opening percentages considered in this study. The results for all cases demonstrated the presence of high pressure at the upstream section and the horizontal bypass section. On the other hand, this high pressure was reduced at the bypass opening section and downstream section of the PIG. This reduction in pressure was due to the presence of the disk which provided obstacle to the fluid flow and therefore reduced the fluid velocity at this section. Moreover, growth of wake which mainly associated with resistance of fluid was identified at downstream. This is due to the presence of disk which created sudden contraction and expansion for the flowing fluid inside the pipe. High turbulence and density difference of the fluids are also another reason of wake. According to fluid mechanics theory, wake is important to determine drag force and other forces experienced by the body. It has significant impact on pressure loss of fluids at the bypass opening section. Growth of wake increases the pressure loss at the downstream section compared to upstream of the PIG.

In addition, by increasing bypass opening percentages from $5 \%$ to $15 \%$ maximum pressure has reduced almost $88 \%, 86 \%$, and $89 \%$ for ethane, butane, and methane, respectively. Additionally, methane provided the lowest pressure value in the pressure contour due to the fluid dynamics properties of methane compared to the other gases. 


\section{Table 6}

Pressure contour of ethane, butane and methane for the five different bypass opening percentages

Bypass Gas Pressure contour

opening

percentages

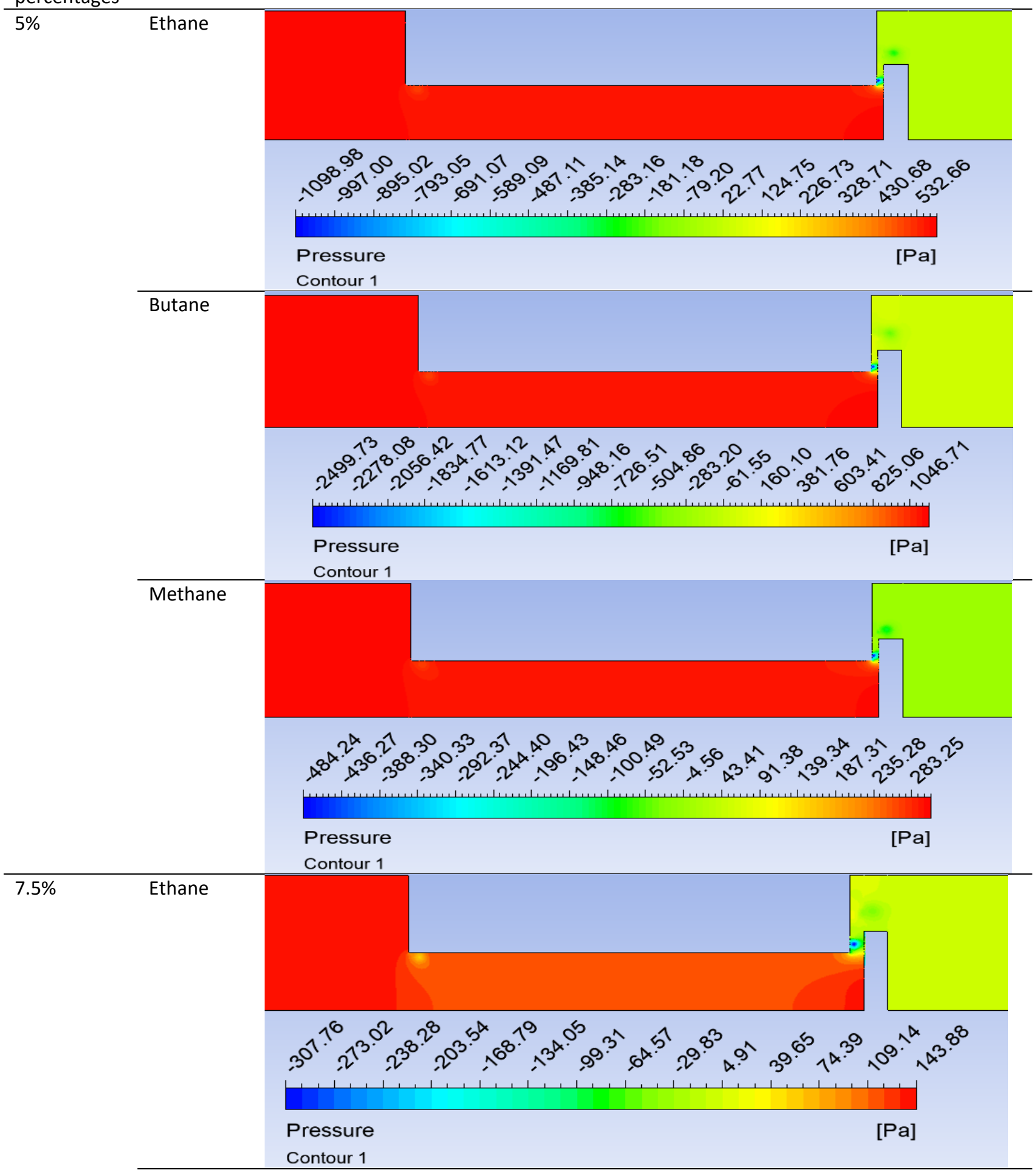




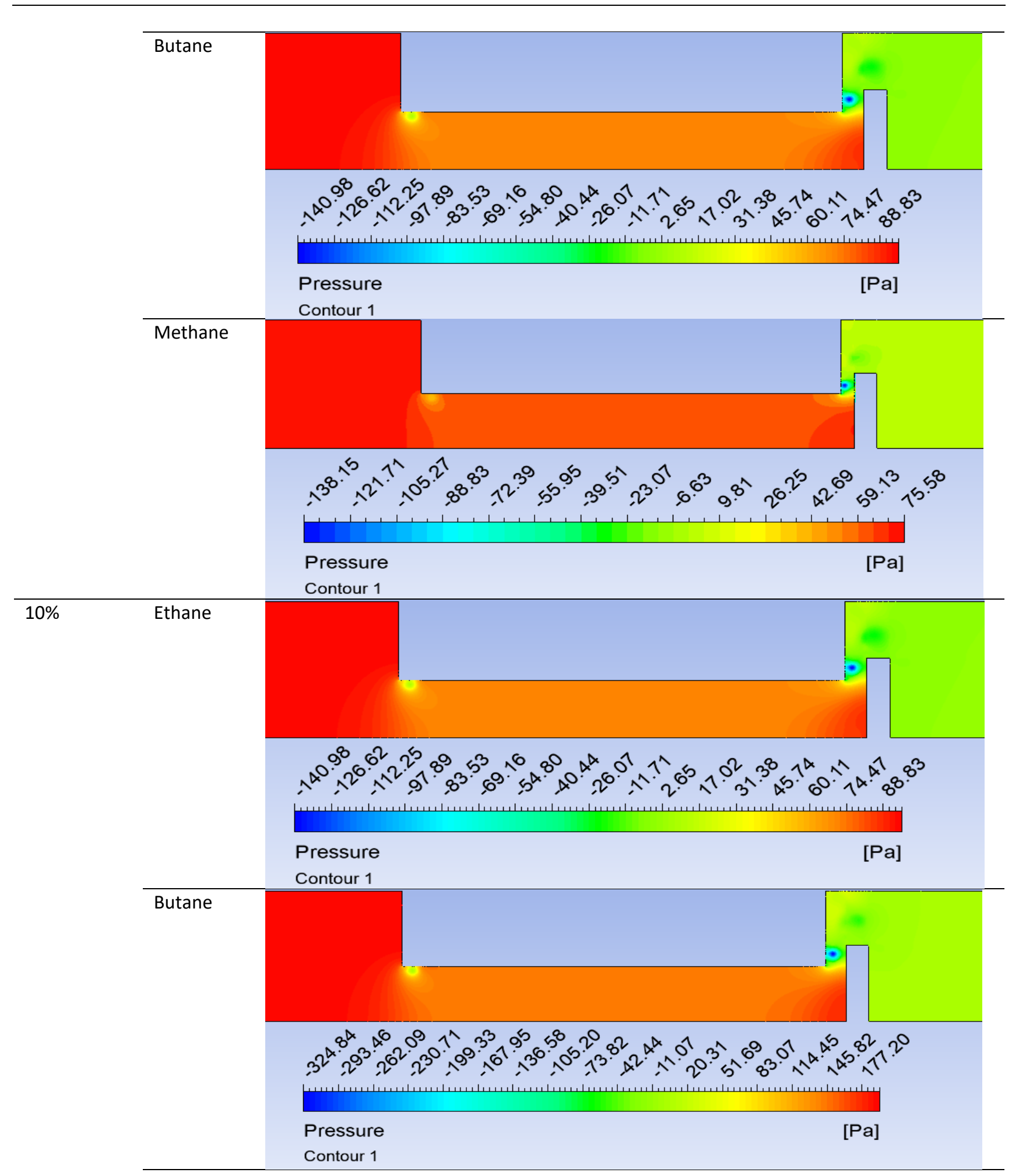




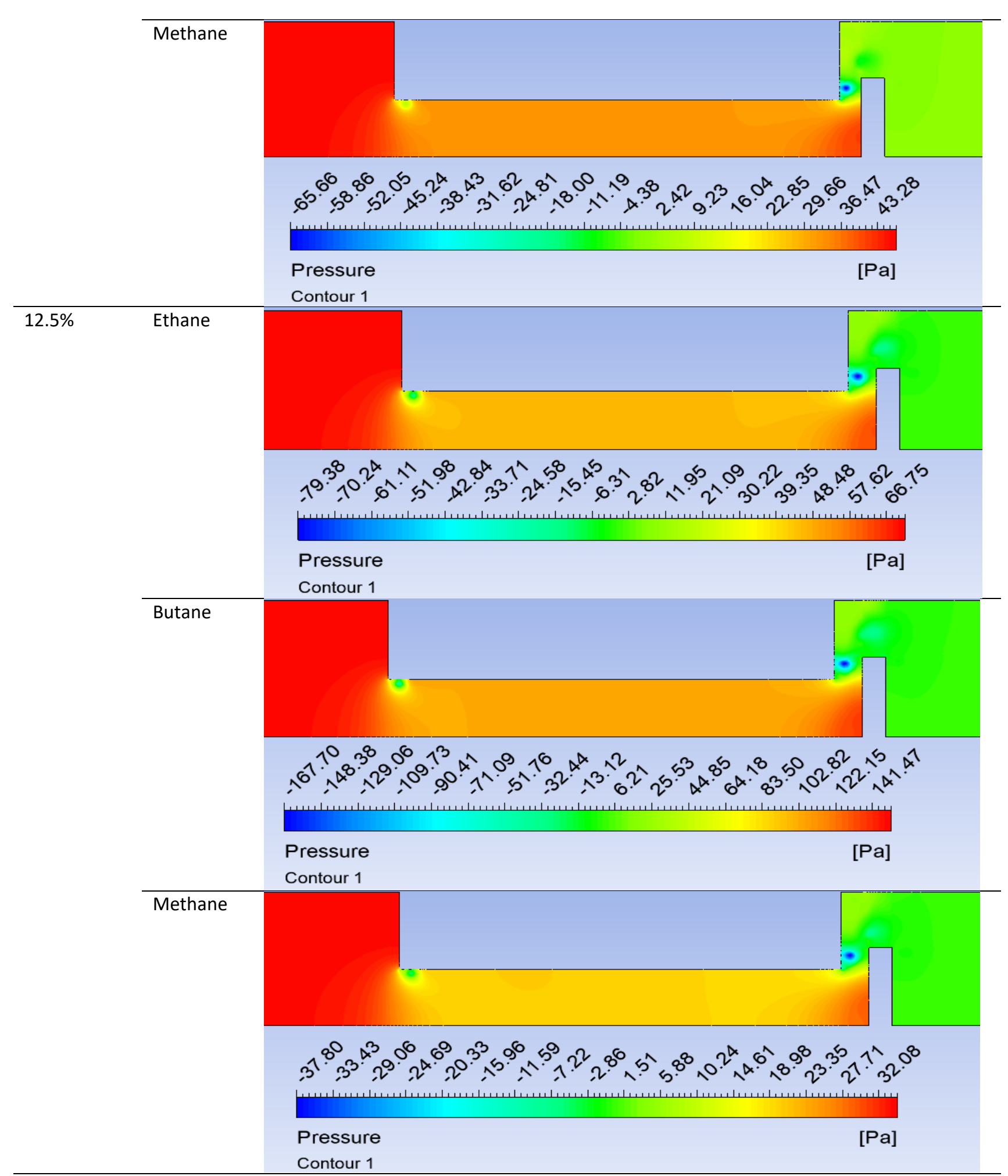




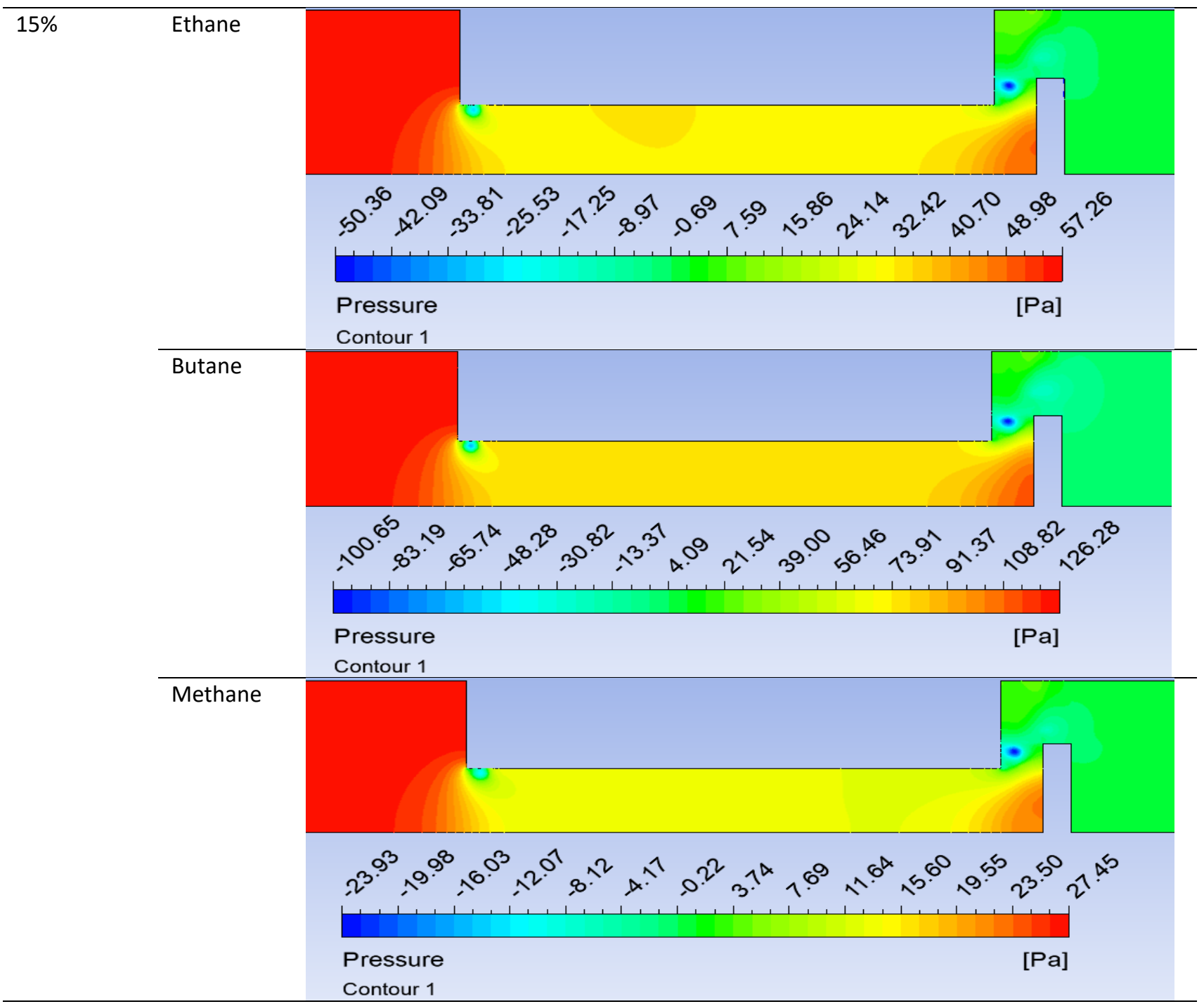

The summaries of the main findings from this study in terms of the velocities and differential pressure of the natural gases around the disk bypass PIG are presented in Table 7 and Table 8. Table 7 represents the comparison of reduction percentage for maximum fluid velocity at horizontal bypass section $\left(v_{2}\right)$ and at bypass opening section $\left(v_{3}\right)$ as well as the differential pressure over the PIG section among ethane, methane, and butane for increasing bypass opening percentages from $5 \%$ to $15 \%$. The reduction percentages were calculated by applying the following equation:

Reduction percentages $(\%)=\frac{\text { value at } 5 \%-\text { value at } 15 \%}{\text { value at } 5 \%} \times 100 \%$

The results demonstrated that as the bypass opening percentage increased from $5 \%$ to $15 \%$, the velocities of all gases at horizontal bypass section and bypass opening section reduced. This result indicated that $15 \%$ bypass opening percentage provided lowest velocities at these sections and therefore is more desirable as compared to other bypass opening percentage values considered in this study. Likewise, for differential pressure, the results shown in Table 7 demonstrates that the differential pressure reduced significantly with $15 \%$ bypass opening percentage compared to the others. Therefore, it can be concluded that flow characteristics in terms of velocities and differential pressure for all gases were the best at $15 \%$ bypass opening percentage. 
Table 7

Reduction percentage (\%) for ethane, methane and butane by increasing bypass opening percentages from $5 \%$ to $15 \%$

\begin{tabular}{llll}
\hline Parameters & Ethane & Butane & Methane \\
\hline $\begin{array}{l}\text { Fluid velocity at horizontal bypass } \\
\text { section, } \boldsymbol{v}_{2}\end{array}$ & 2.1 & 1.3 & 2.3 \\
$\begin{array}{l}\text { Fluid velocity at the bypass } \\
\begin{array}{l}\text { opening section, } \boldsymbol{v}_{3} \\
\text { Differential pressure }\end{array}\end{array}$ & 28.28 & 40.43 & 21.21 \\
\hline
\end{tabular}

Meanwhile, Table 8 shows the results comparison among ethane, methane, and butane for the best opening percentage considered in this study which was found to be $15 \%$. From this table, methane resulted in the lowest fluid velocity of $v_{2}$ and $v_{3}$ compared to ethane and butane. Additionally, differential pressure of methane was also found to be the lowest at this percentage compared to other gases. On the other hand, butane shows the highest values of these results. Therefore, it can be predicted that during pigging operation, the PIG would perform with the lowest speed and result in lowest differential pressure inside methane flowing pipelines compared to ethane and butane.

Based on these key findings, it can be concluded that flow characteristics in terms of velocities and differential pressure were the best at $15 \%$ bypass opening percentage with methane as the fluid compared to other cases.

\section{Table 8}

Flow characteristics of ethane, methane and butane at $15 \%$ bypass opening percentages

\begin{tabular}{|c|c|c|c|}
\hline Variables & Ethane (15\%) & Butane (15\%) & $\begin{array}{l}\text { Methane } \\
(15 \%)\end{array}$ \\
\hline Reynolds Number & 58786 & 151958 & 26569 \\
\hline $\begin{array}{l}\text { Fluid velocity at horizontal } \\
\text { bypass section, } \boldsymbol{v}_{2}(\mathrm{~m} / \mathrm{s})\end{array}$ & 5.08 & 5.27 & 4.80 \\
\hline $\begin{array}{l}\text { Fluid velocity at the bypass } \\
\text { opening section, } \boldsymbol{v}_{3}(\mathrm{~m} / \mathrm{s})\end{array}$ & 0.79 & 0.85 & 0.76 \\
\hline Differential pressure $(\mathrm{Pa})$ & 72.65 & 156.65 & 34.95 \\
\hline
\end{tabular}

\subsection{Correlation of Differential Pressure}

In order to predict differential pressure between upstream and downstream section of the PIG which essentially drives the PIG forward, a correlation was developed by using curve fitting of data in this study that enables quick prediction of this important flow characteristics in future use. The developed correlation is a function of various parameters of the PIG geometry including the bypass opening percentage as well as gas density and inlet velocity, which is given by

$\Delta P=\left(\frac{L_{P I G}}{D} \rho \frac{v_{i n}^{2}}{2}\right)\left(\frac{H}{d}\right)^{a} h$

where $D$ is pipe diameter; $d$ is horizontal bypass PIG diameter; $h$ is bypass opening percentages; $H$ is disk diameter; $L_{P I G}$ is horizontal bypass length of PIG; $\rho$ is the gas density; and $v_{i n}$ is the inlet velocity of the gas.

Meanwhile, $a$ in Eq. (12) is a correlation factor and the values are given in Table 9 for different $h$ values. 


\section{Table 9}

Values of correlation factor $(a)$ for different $h$ conditions

\begin{tabular}{ll}
\hline$h(\%)$ & $a$ \\
\hline 5 & 29.5 \\
7.5 & 24.6 \\
10 & 22 \\
12.5 & 20.5 \\
15 & 19.4 \\
\hline
\end{tabular}

Figure 8 demonstrates comparison between results from the developed correlation and simulations for ethane, butane and methane. It can be seen from this figure that the results from developed correlation provided similar trend with the simulation results. The percentage of maximum deviation was $3.8 \%$ for ethane, $7.7 \%$ for butane, and $6.6 \%$ for methane, respectively. Moreover, the root mean square error (RMSE) between the correlation and simulation results was obtained to be 0.44 for ethane, 0.52 for butane and 0.49 for methane, respectively. The observed maximum deviation and RMSE values indicated good agreement between correlation and simulation results. Therefore, it can be concluded that the developed correlation in this study can be used to predict the differential pressure of gases around disk bypass PIG under the conditions considered in this study.

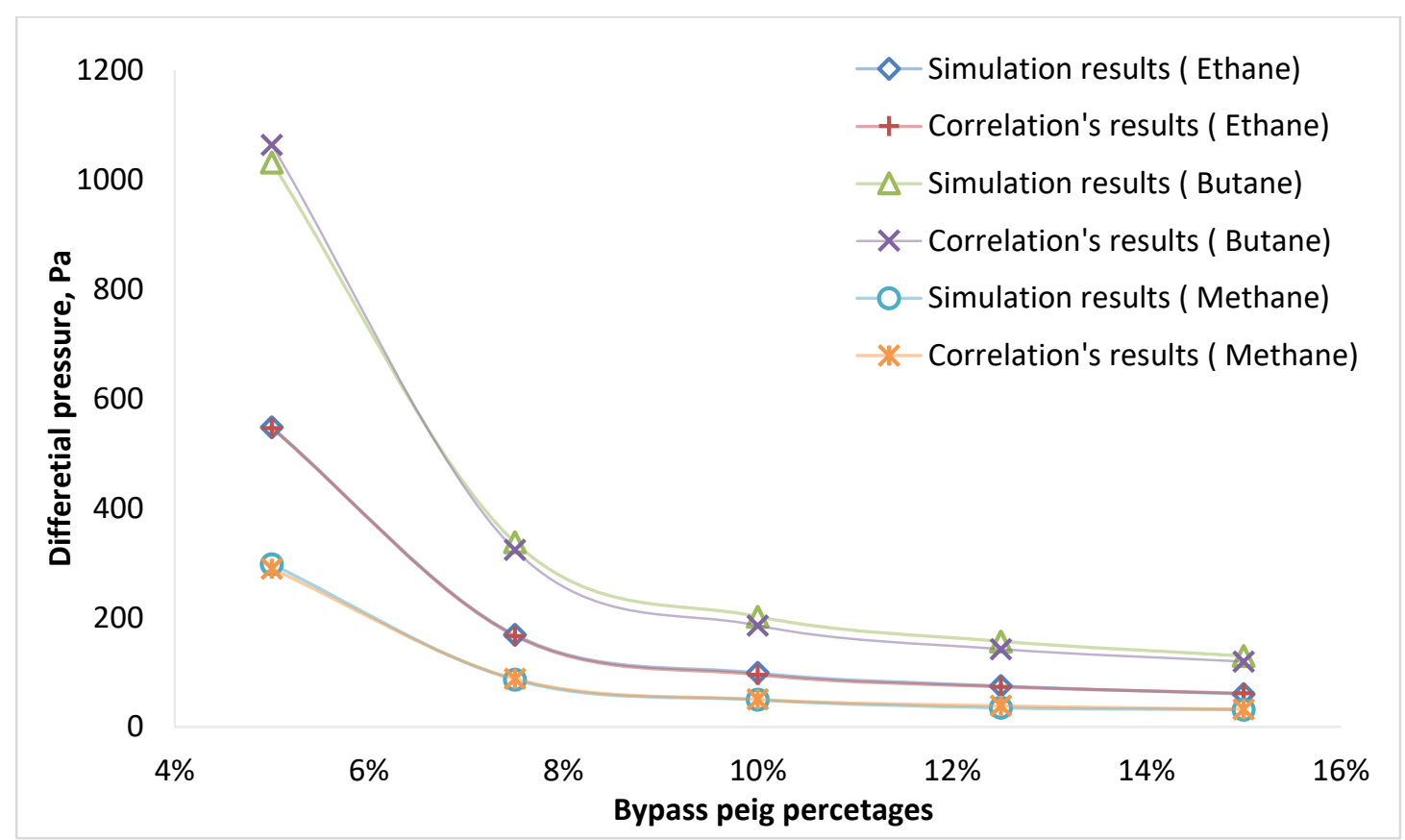

Fig. 8. Comparison of correlation and simulation results for differential pressure as a function of bypass opening percentages for ethane, butane and methane

\section{Conclusions}

Flow characteristics of methane, ethane and butane around disk bypass PIG were analysed in this study using computational fluid dynamics approach. The key findings from this study are the following.

a) With the increase of bypass opening percentages $5 \%$ to $15 \%$, fluid velocity at bypass opening section has reduced $28.28 \%, 40.43 \%$, and $21.21 \%$ for ethane, butane, and methane, respectively, while the differential pressure has reduced $88 \%, 86 \%$, and $89 \%$ for these natural 
gases, respectively. This key finding indicated that bypass opening percentage of $15 \%$ provided the best flow characteristics in terms of both velocity and differential pressure in comparison to other percentages considered in this study.

b) At $15 \%$ bypass opening percentage, methane resulted in the lowest fluid velocity at bypass opening section compared to ethane and butane. Additionally, methane also resulted in lowest differential pressure at this percentage compared to other gases. Therefore, it can be concluded that flow characteristics in terms of velocities and differential pressure were the best at $15 \%$ bypass opening percentage with methane as the fluid compared to other cases.

c) A correlation of differential pressure was also developed for first time in this study that can be used to predict differential pressure of natural gases around disk bypass PIG under the conditions considered in this study. The developed correlation agreed well with simulation results with maximum deviation of $3.8 \%$ for ethane, $7.7 \%$ for butane, and $6.6 \%$ for methane.

\section{Acknowledgement}

This work was financially supported by industrial grant from Eureka Efektif Sdn. Bhd. under vote number 6300211 (Universiti Putra Malaysia) for which authors greatly acknowledged.

\section{References}

[1] Wang, Qian, Cem Sarica, and Michael Volk. "An experimental study on wax removal in pipes with oil flow." Journal of Energy Resources Technology 130, no. 4 (2008). https://doi.org/10.1115/1.3000136

[2] Tolmasquim, S. T., and A. O. Nieckele. "Design and control of pig operations through pipelines." Journal of Petroleum Science and Engineering 62, no. 3-4 (2008): 102-110. https://doi.org/10.1016/i.petrol.2008.07.002

[3] Zhang, Hang, Shimin Zhang, Shuhai Liu, Xiaoxiao Zhu, and Biao Tang. "Chatter vibration phenomenon of pipeline inspection gauges (PIGs) in natural gas pipeline." Journal of Natural Gas Science and Engineering 27 (2015): 11291140. https://doi.org/10.1016/i.jngse.2015.09.054

[4] Tu, Qing, Qingyou Liu, Shouhong Ji, Tao Ren, and Yujia Li. "Speed Simulation of Hydraulic Automatic SpeedControlled Pipeline Inspection Gauge in Liquid Pipelines." Journal of Pressure Vessel Technology 142, no. 1 (2020). https://doi.org/10.1115/1.4045132

[5] Kim, Seungman, and Yutaek Seo. "Simulation and Parametric Study of Speed Excursion of PIG in Low-Pressure Gas Pipeline." Paper presented at the The 30th International Ocean and Polar Engineering Conference, Virtual, October 2020.

[6] Liang, Xiaoyun. "Numerical study of flow around bypass pigs." Master's thesis, Delft University of Technology, 2015.

[7] Hendrix, M. H. W., B. Sanderse, W-P. Breugem, and R. A. W. M. Henkes. "Simulation of slug propagation for by-pass pigging in two-phase stratified pipe flow." In BHR 19th International Conference on Multiphase Production Technology. BHR Group, 2019.

[8] Liu, Chang, Yungang Wei, Yuguang Cao, Shihua Zhang, and Yongtai Sun. "Traveling ability of pipeline inspection gauge (PIG) in elbow under different friction coefficients by 3D FEM." Journal of Natural Gas Science and Engineering 75 (2020): 103134. https://doi.org/10.1016/i.jngse.2019.103134

[9] Nguyen, Tan Tien, Hui Ryong Yoo, Yong Woo Rho, and Sang Bong Kim. "Speed control of PIG using bypass flow in natural gas pipeline." In ISIE 2001. 2001 IEEE International Symposium on Industrial Electronics Proceedings (Cat. No. 01TH8570), vol. 2, pp. 863-868. IEEE, 2001.

[10] Chen, Jianheng, Limin He, Xiaoming Luo, Lin Lu, Hailong Zhang, Xiaowei Li, Haixiao Liu, and Songtao He. "Bypass pigging technology on amelioration of pigging-induced liquid flow: An experimental and modelling study." Ocean Engineering 198 (2020): 106974. https://doi.org/10.1016/i.oceaneng.2020.106974

[11] Hendrix, M. H. W. "Experiments and modelling for by-pass pigging of pipelines." PhD diss., Delft University of Technology, 2020.

[12] Zhang, Zengmeng, Yong Yang, Jiaoyi Hou, and Yongjun Gong. "Modeling and simulation on speed prediction of bypass pipeline inspection gauge in medium of water and crude oil." Measurement and Control (2020): 0020294020947123.

[13] Nguyen, Tan Tien, Sang Bong Kim, Hui Ryong Yoo, and Yong Woo Rho. "Modeling and simulation for pig with bypass flow control in natural gas pipeline." KSME International Journal 15, no. 9 (2001): 1302-1310. https://doi.org/10.1007/BF03185671 
[14] Zhu, Xiaoxiao, Shimin Zhang, Guibin Tan, Deguo Wang, and Wenming Wang. "Experimental study on dynamics of rotatable bypass-valve in speed control pig in gas pipeline." Measurement 47 (2014): 686-692. https://doi.org/10.1016/i.measurement.2013.08.060

[15] Botros, K. K., and H. Golshan. "Dynamics of pig motion in gas pipelines." In AGA-Operations Conference and Biennial Exhibition, David L. Lawrence Convention Center, Pittsburgh, Pennsylvania, pp. 1-16. 2009.

[16] Esmaeilzadeh, F., D. Mowla, and M. Asemani. "Mathematical modeling and simulation of pigging operation in gas and liquid pipelines." Journal of Petroleum Science and Engineering 69, no. 1-2 (2009): 100-106. https://doi.org/10.1016/i.petrol.2009.08.006

[17] Esmaeilzadeh, Feridun, Maryam Asemani, and Dariush Mowla. "Modeling of pig operations in natural gas and liquid pipeline." In SPE Annual Technical Conference and Exhibition. Society of Petroleum Engineers, 2006. https://doi.org/10.2118/102049-MS

[18] Singh, A., and R. A. W. M. Henkes. "CFD modeling of the flow around a by-pass pig." In 8th North American Conference on Multiphase Technology. BHR Group, 2012.

[19] Hendrix, M. H. W., H. P. Ijsseldijk, W-P. Breugem, and R. A. W. M. Henkes. "Development of speed controlled pigging for low pressure pipelines." In 18th International Conference on Multiphase Production Technology. BHR Group, 2017.

[20] Hendrix, M. H. W., C. M. Graafland, and R. A. J. van Ostayen. "Frictional forces for disc-type pigging of pipelines." Journal of Petroleum Science and Engineering 171 (2018): 905-918. https://doi.org/10.1016/i.petrol.2018.07.076

[21] Zhu, Xiaoxiao, Wei Wang, Shimin Zhang, and Shuhai Liu. "Experimental research on the frictional resistance of fluiddriven pipeline robot with small size in gas pipeline." Tribology Letters 65, no. 2 (2017): 49. https://doi.org/10.1007/s11249-017-0830-z

[22] Chen, Jianheng, Limin He, Xiaoming Luo, Hailong Zhang, Xiaowei Li, Haixiao Liu, Songtao He, and Lin Lu. "Characterization of bypass pig velocity in gas pipeline: An experimental and analytical study." Journal of Natural Gas Science and Engineering 73 (2020): 103059. https://doi.org/10.1016/j.jngse.2019.103059

[23] Korban, J. E. A. "CFD modelling of bypass pigs." PhD diss., Master's thesis, Delft University of Technology, the Netherlands, 2014.

[24] Idelchik, I. E., and E. Fried. "Handbook of hydraulic resistance." Hemisphere Publising Corp., USA (1986).

[25] Azpiroz, J. E., M. H. W. Hendrix, W-P. Breugem, and R. A. W. M. Henkes. "CFD modelling of bypass pigs with a deflector disk." In 17th International Conference on Multiphase Production Technology. BHR Group, 2015.

[26] Mahammedi, Abdelkader, Houari Ameur, Younes Menni, and Driss Meddah Medjahed. "Numerical study of turbulent flows and convective heat transfer of Al2O3-water nanofluids in a circular tube." Journal of Advanced Research in Fluid Mechanics and Thermal Sciences 77, no. 2 (2021): 1-12. https://doi.org/10.37934/arfmts.77.2.112

[27] Bellahcene, Lahcene, Djamel Sahel, and Aissa Yousfi. "Numerical Study of Shell and Tube Heat Exchanger Performance Enhancement Using Nanofluids and Baffling Technique." Journal of Advanced Research in Fluid Mechanics and Thermal Sciences 80, no. 2 (2021): 42-55. https://doi.org/10.37934/arfmts.80.2.4255

[28] Wong, M. K., L. Chang Sheng, C. S. Nor Azwadi, and G. A. Hashim. "Numerical study of turbulent flow in pipe with sudden expansion." Journal of Advanced Research in Fluid Mechanics and Thermal Sciences 6, no. 1 (2015): 34-48.

[29] Hamzah, Mushtaq Talib, and Ali Lateef Tarish. "Numerical Study of The Effect of Corrugated Wall on The Turbulent Forced Convective Heat Transfer and Fluid Flow Through a Forward-facing Step Channel." Journal of Advanced Research in Fluid Mechanics and Thermal Sciences 67, no. 1 (2020): 33-42.

[30] Nfawa, Sadeq Rashid, Abd Rahim Abu Talib, Siti Ujila Masuri, Adi Azriff Basri, and Hasril Hasini. "Heat transfer enhancement in a corrugated-trapezoidal channel using winglet vortex generators." CFD Letters 11, no. 10 (2019): 69-80.

[31] Talbizadeh, Asghar, and Mohammad Mehdi Keshtkar. "Numerical and experimental study on a bypass pig motion in oil transmission pipeline: a case study." Journal of Petroleum Exploration and Production Technology 10, no. 7 (2020): 3007-3023. https://doi.org/10.1007/s13202-020-00893-6

[32] Versteeg, Henk Kaarle, and Weeratunge Malalasekera. An introduction to computational fluid dynamics: the finite volume method. Pearson education, 2007. 